\title{
Use of Alternative Hydrogeological Conceptual Models to Assess the Potential Impact of Climate Change on Groundwater Sustainable Yield in Central Huai Luang Basin, Northeast Thailand
}

\author{
Kewaree Pholkern ${ }^{1,2}$, Phayom Saraphirom ${ }^{1,3, *}$, Vincent Cloutier ${ }^{4}$ and Kriengsak Srisuk $^{1}$ \\ 1 Groundwater Resources Research Institute, Khon Kaen University, Khon Kaen 40002, Thailand; \\ rekawee@hotmail.com (K.P.); kriengsk@kku.ac.th (K.S) \\ 2 Department of Environmental Engineering, Faculty of Engineering, Khon Kaen University, \\ Khon Kaen 40002, Thailand \\ 3 Department of Agricultural Engineering, Faculty of Engineering, Khon Kaen University, \\ Khon Kaen 40002, Thailand \\ 4 Groundwater Research Group, Research Institute on Mines and Environment, Université du Québec en \\ Abitibi-Témiscamingue, Rouyn-Noranda, QC J9X 5E4, Canada; vincent.cloutier@uqat.ca \\ * Correspondence: payosa@kku.ac.th; Tel.: +66-43-202-700
}

Received: 10 January 2019; Accepted: 28 January 2019; Published: 31 January 2019

\begin{abstract}
Sustainable management of groundwater resources is essential for sound groundwater development, especially in sensitive salt-affected areas. In Northeast Thailand, the Central Huai Luang Basin, underlain by rock salt, is the source of groundwater and soil salinity. The future sustainable groundwater development yield was assessed under the plausible uncertainty of hydrogeological and projected climate scenarios that could impact the groundwater system. The SEAWAT and HELP3 models were used to simulate groundwater system. The four alternative scenarios of hydrogeological conceptual models were formulated to determine the impact on groundwater system and sustainable groundwater yield. In addition, impacts of projected climate conditions on each alternative model were explored. The results indicate that variable depths and thicknesses of rock salt layers have a higher impact on groundwater salinity distribution and sustainable yield estimations than model boundary conditions. Groundwater salinity, shallow water table areas, and sustainable yield projections vary substantially depending on the possible conceptual model scenarios. It is clear that the variable hydrogeological models affect groundwater sustainable yields.
\end{abstract}

Keywords: hydrogeology; groundwater management; numerical modeling; salinity; SEAWAT; HELP3; sustainable groundwater

\section{Introduction}

Udon Thani Province is the one of the most important socioeconomic provinces of Northeast (NE) Thailand [1]. Agricultural, food production, and community areas of Udon Thani Province are located in the Central Huai Luang Basin (CHLB). The CHLB is underlain by rock salt layers of the Maha Sarakham formation, a source of saline groundwater, surface water, and soils. Groundwater flow is a significant mechanism for spreading saline water in this basin. Due to the limitations of surface water storage and conveyance structure, groundwater also plays an important role as the major source of the public and agricultural water supply in many areas. While groundwater governance in this area is still ineffectively implemented, the poor control of groundwater development and impact of 
climate variability have led to serious problems in terms of the substantial withdrawal of groundwater level, lateral and vertical spreading of saline groundwater [2]. Extensive groundwater investigation is expected to be improved for long-term sustainable groundwater development and governance in this basin.

In order to assess the groundwater potential, a numerical model was used as a tool for simulating several future scenarios. The first and most important step in developing groundwater models is to establish a conceptual model or model structure of the hydrogeological system [3-5]. Usually, groundwater model studies are represented by only a single hydrogeological conceptual model [4-6]. Traditional groundwater modeling had not given enough attention to formulating a groundwater conceptual model [6,7]. This leads to bias and incorrect projection results when considering only one conceptual model and neglecting possible others. In addition, the correctness of the groundwater conceptual model cannot be assured by an excellent model calibration [6,8]. The alternative conceptual model has received more attention in groundwater applications in the last decade [4,6,9]. Many studies point out that $5-30 \%$ of predictive uncertainty is derived from the conceptual model, so it is more significant than parameter uncertainty (e.g., $[4,7,10])$. Therefore, the alternative hydrogeological conceptual model should be given attention for its groundwater predictive capability.

Any hydrogeological conceptual model must assess how future climate change will impact on groundwater in several ways. Intensive research into climate change indicates that impacts on the hydrological system and water resources will occur at a global scale [11-14]. The main focus of the research on climate change related to groundwater has been the impacts of changing the amount and pattern of precipitation and temperature (e.g., [15-23]). Changes in climatic variables can significantly alter the hydrologic cycle and groundwater recharge, which control water level and salinity distribution. These consequences could affect the ground surface and land capability for agriculture activities $[15,20,23,24]$, especially in Northeast Thailand, which already has problems with groundwater and soil salinity. Several earlier studies that predicted future climate change in Thailand for different purposes [25-32] indicated an increasing trend in the average annual rainfall and temperature from 2016 to 2056. Therefore, climate change could be one of the sensitive factors impacting groundwater potential and salinity distribution in the future.

Due to the complexity of the hydrogeological condition, such as the shape and thickness of the rock salt layers underlying the CHLB, it would be risky to use the results of sustainable yield estimation from a single hydrogeological conceptual model for decision-making to govern groundwater development in the basin. Therefore, a set of alternative hydrogeological conceptual models, as well as possible boundary conditions of groundwater flow and saline water transport, were established to assess the impacts of future climate scenarios on groundwater sustainable yield of the CHLB for the next 30 years. The range of the sustainable yields of the CHLB under uncertainty condition could be used as robust information for the decision makers to manage and govern groundwater development in a sustainable manner.

\section{The Study Area}

The CHLB covers an area of approximately $1529 \mathrm{~km}^{2}$ and is located in the Udon Thani and Nong Bua Lamphu Provinces, in Northeast Thailand (Figure 1), part of the Mekong River basin. Hilly and rolling hill topographic terrains are commonly found in the south and north regions, with the highest elevation of $564 \mathrm{~m}$ above mean sea level (MAMSL) and peneplain morphology found at the central to northeast side and along the Huai Luang River at the low elevation of 161 MAMSL (Figure 2). The CHLB has a tropical monsoon climate with an average annual rainfall of $1268.6 \mathrm{~mm}$, which showed an increasing trend between 1984 and 2015 [33,34]. Almost 90\% of the average annual rainfall is distributed in May through October. The average daily temperature is $27.0^{\circ} \mathrm{C}$ and also has a slightly increasing trend. January is the coolest month, with a daily temperature of about $22.4{ }^{\circ} \mathrm{C}$, and April is the hottest month, with $29.8^{\circ} \mathrm{C}$ [33]. The average evaporation from the Class A Pan measurement is $1683 \mathrm{~mm} /$ year [33]. 


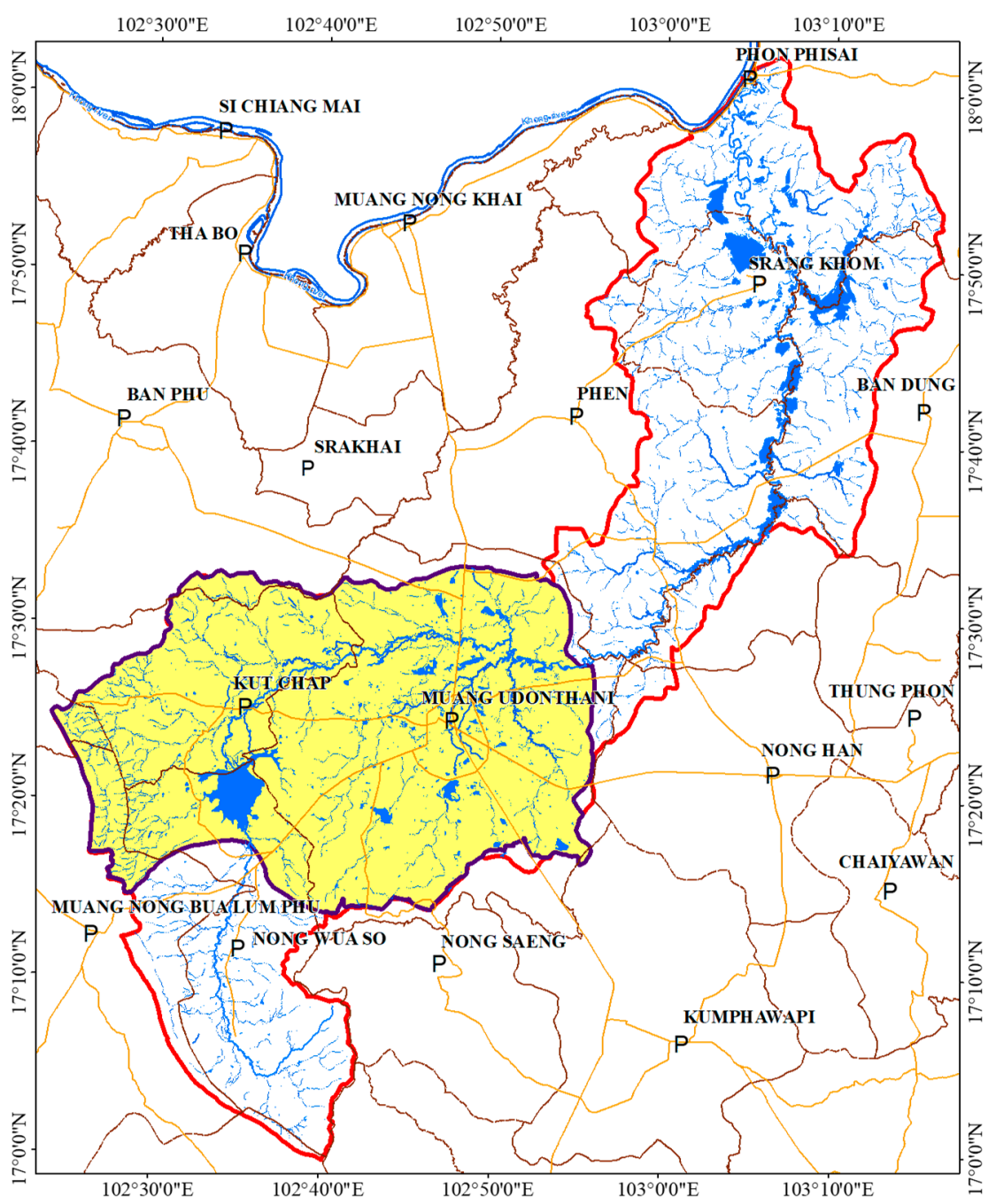

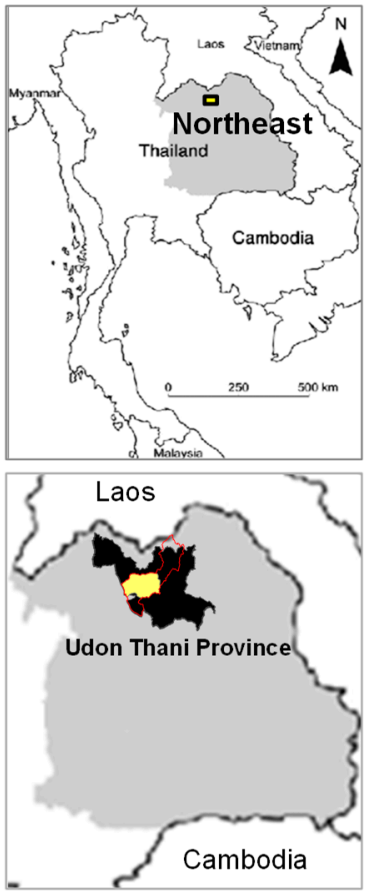

Explanation

O District

- Perennial stream Intermittent stream Road Water body District boundary Huai Luang basin Study area

Figure 1. Location of the CHLB in the Huai Luang River Basin, NE Thailand.

Agricultural areas, where the main products are rice, sugarcane, and cassava, are common in the basin. Paddy fields are located along the Huai Luang River floodplain, covering an area of about $40 \%$ of the basin. The northwest and southwest regions covered by field crops form about $23 \%$ of the basin. The initial surface water resource is the Huai Luang River and Huai Luang reservoir. The Huai Luang River flows from west to east. The total volume of the flow throughout CHLB is approximately 262.4 Million Cubic Meters/year (MCM/year). The flow of the Huai Luang River varies extensively; about $97 \%$ of the total annual flow occurs during the wet season of May through October, and about $3 \%$ of flow occurs during the dry season of November through April [34]. The Huai Luang Reservoir, a major water source for water supply and irrigation, is located in the southwestern part of the basin. The water quality of the Huai Luang River and its tributary is slightly brackish, with electrical conductivities of greater than $1500 \mu \mathrm{S} / \mathrm{cm}$ or Total Dissolved Solids (TDS) greater than $1000 \mathrm{mg} / \mathrm{L}$ in the dry season. Saline soils are commonly found in the lower elevations along the Huai Luang floodplain.

In order to develop the conceptual groundwater flow model, field investigations and hydrogeological mapping of surface manifestations including soil properties, soil salinity, river cross sections, surface water level and quality, groundwater level and quality, locations and well records of water wells, well and piezometer drilling and pumping tests, and dispersivity tests were conducted from September 2014 to December 2015. 


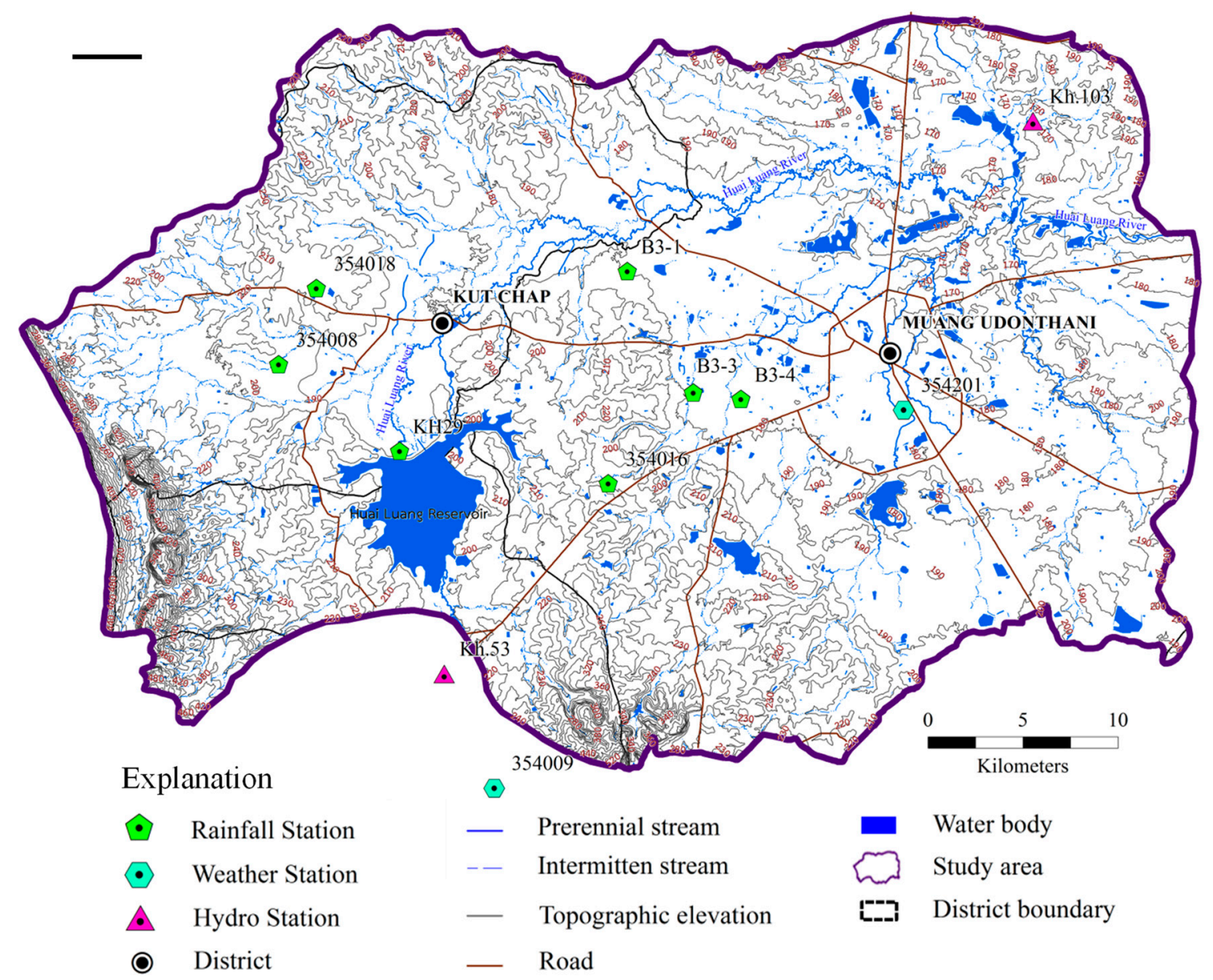

Figure 2. Topographic elevations (MAMSL) and meteorological and hydrological stations in the CHLB.

\subsection{Geology}

The geology of the CHLB was compiled, modified, and reinterpreted from a geological map of the Department of Mineral Resources [35], potash investigation wells [36], a previous study of Cotanont [37], and drilling for water wells and piezometers with depths of 8-81 $\mathrm{m}$ from the current project [38]. The study area is underlain by nine geologic formations, characterized, from the youngest to the oldest formations, as follows: Alluvium (Qa), Terrace (Qt), Phutok (Tpt), Maha Sarakham (Kms), Khok Kraut (Kkk), Phu Phan (Kpp), Sao Khua (Ksk), Phra Wihan (JKpw), and Phu Kradung (Jpk) formations (Figures 3 and 4). Alluvium formation mainly consists of a combination of sand, gravel, and clay. It was deposited along the floodplain of the Huai Luang River and the sediments were deposited in age from the mid- to late Quaternary. Another Quaternary formation in this area is a Terrace formation that consists of gravel and sand; it can be found in the central to southeastern part of the study area. This alluvium is underlain by the Phutok formation, which is composed of sandstone with reddish brown color, medium grain, and siltstone. Large-scale cross bedding, desiccation cracks, and coarsening upward sequences can be commonly found locally. The total thickness of the Phutok formation varies from 10 to $250 \mathrm{~m}$ and the formation crops out all over the basin except in the west. The Phutok formation can be divided into two units (upper and lower) that range in age from Tertiary to upper Cretaceous. The upper unit consists of cross-bedded, fine-grained reddish sandstones interbedded with siltstones, underlain by reddish brown siltstones interbedded claystone of the lower unit. Underlying the Phutok formation is the Maha Sarakham formation, which is composed of claystone interbedded with rock salt, gypsum, anhydrite, and potash. The formation is present at the depths of 30-500 m below the ground surface. This formation does not outcrop in the study area as it is covered by the younger formation (Qt, $\mathrm{Qa}$, and $\mathrm{Tpt})$. However, its presence is critical with regard to 
water quality in the region due to the existence of rock salt layers. A distinct contact of claystone and rock salt was found in the exploration potash wells at a depth of 25-180 m below the ground surface. Khok Kruat formation was deposited underneath Maha Sarakham formation, which is composed of medium to coarse-grain sandstone, siltstone, claystone, and conglomerate, of reddish-brown color, and was deposited in the early Cretaceous. Khok Kruat formation can be found in the west and south of the basin and is underlain by medium to coarse-grained sandstone, conglomerate sandstone, and conglomerate, whitish gray in Phu Phan formation (early Cretaceous). Sao Khua formation is overlain by Phu Phan formation and is composed of sandstone, siltstone, claystone, and conglomerate, reddish-brown and medium- to coarse-grained (early Cretaceous). Sao Khua formation is underlain by Phra Wihan formation at the west and south of the basin and consists of sandstone, conglomerate sandstone, and conglomerate, medium-grained, whitish-gray color, and with a depositional age from the mid-Jurassic to the early Cretaceous. The lowest formation, which can be found in the west and south, is the Phu Kradung formation. This formation consists of sandstone, siltstone, claystone, and conglomerate, reddish-brown, ranging from medium- to coarse-grained, deposited during the mid- to late Jurassic.

\subsection{Hydrogeology}

The main aquifers are sand and gravel of Alluvium and Terrace formations, and sandstone and siltstone of the Phutok and Khok Kruat formations. Results from 10 pumping tests with observation wells and two sites of dispersivity tests in this study, and 24 single well tests [37], were used to estimate the range of transmissivity, horizontal hydraulic conductivity, storage coefficient, and longitudinal dispersivity values for the CHLB aquifers (Table 1). Seven hydrogeological units were identified for formulating a conceptual framework of the groundwater model classified in the study area. Alluvium unit ( $\mathrm{Al})$ is one of the major aquifers, composed of sand, clay, and gravel and located along the flood plain of the Huai Luang River, with a thickness of about 10-45 m. Terrace unit (Te) is one of the sand and gravel aquifers found in upland areas in the southern part of the study area, from Huai Luang River to the middle part of the study area, with a thickness of 10-50 m. The Upper Phutok unit (Upt), with a thickness of 10-200 m, consists of fine-to-medium sandstone and siltstone. The formation is easily fractured and is usually a productive aquifer, found in the northwest and northeast parts of the study area. The Lower Phutok unit (Lpt), which consists of clay and claystone with an average thickness of about 10 to $300 \mathrm{~m}$, is underlain by a layer of rock salt. Maha Sarakham unit (Ms) is a very low-permeability unit of rock salt, anhydrite, and gypsum interbedded with mudstone deposited under the Lpt Unit with the thickness varying from 50 to $600 \mathrm{~m}$. The Khok Kruat unit (Kk) is found at the foot of the mountain, consisting of siltstone and sandstone with a thickness of 50-400 m. Underlying the Khok Kruat unit, the Lower Khorat Group unit (Lkg), consists of sandstone, siltstone, claystone, and a conglomerate of the Phu Phan, Sao Khua, Phra Wihan, and Phu Kradung formations (Figure 4).

Table 1. Estimated ranges of aquifer properties by hydrostratigraphic units.

\begin{tabular}{|c|c|c|c|c|c|c|}
\hline Hydrogeologic Units & $\mathrm{Kh}(\mathrm{m} / \mathrm{s})$ & $\mathrm{Kv}(\mathrm{m} / \mathrm{s})$ & $\mathrm{s}\left(\mathrm{m}^{-1}\right)$ & $S(-)$ & Sy (-) & DI (m) \\
\hline Alluvium (Al) & $1.1 \times 10^{-7}-1.1 \times 10^{-5}$ & $1.1 \times 10^{-7}-1.1 \times 10^{-5}$ & $1.0 \times 10^{-2}-1.0 \times 10^{-5}$ & - & $0.01-0.35$ & $30-500$ \\
\hline Terrace Deposit (Te) & $1.0 \times 10^{-5}-5.0 \times 10^{-2}$ & $5.0 \times 10^{-6}-5.0 \times 10^{-3}$ & $1.0 \times 10^{-2}-1.0 \times 10^{-5}$ & - & $0.01-0.30$ & $40-600$ \\
\hline Upper phutok (Upt) & $3.7 \times 10^{-7}-1.8 \times 10^{-6}$ & $3.7 \times 10^{-8}-4.8 \times 10^{-7}$ & $1.0 \times 10^{-3}-1.0 \times 10^{-5}$ & $0.01-0.20$ & - & $30-200$ \\
\hline Rock salt (RS) & $1.0 \times 10^{-14}-1.0 \times 10^{-15}$ & $1.0 \times 10^{-14}-1.0 \times 10^{-16}$ & $1.0 \times 10^{-5}-1.0 \times 10^{-8}$ & $0.01-0.10$ & - & $3-50$ \\
\hline Khok Kruat (Kk) & $7.5 \times 10^{-8}-5.8 \times 10^{-5}$ & $7.5 \times 10^{-9}-5.8 \times 10^{-6}$ & $1.0 \times 10^{-3}-1.0 \times 10^{-5}$ & $0.01-0.25$ & - & $20-100$ \\
\hline Lower Khorat Group (Lkg) & $5.0 \times 10^{-9}-5.0 \times 10^{-7}$ & $5.0 \times 10^{-10}-5.0 \times 10^{-8}$ & $1.0 \times 10^{-3}-1.0 \times 10^{-5}$ & $0.01-0.25$ & - & $30-200$ \\
\hline
\end{tabular}

Note: Horizontal hydraulic conductivity $=\mathrm{Kh}$, Vertical hydraulic conductivity $=\mathrm{Kv}$, Storativity (for confined aquifer) $=\mathrm{S}$, Specific yield (for unconfined aquifer) $=\mathrm{Sy}$, Specific storage $=\mathrm{Ss}$, Longitudinal dispersivity = DI . 


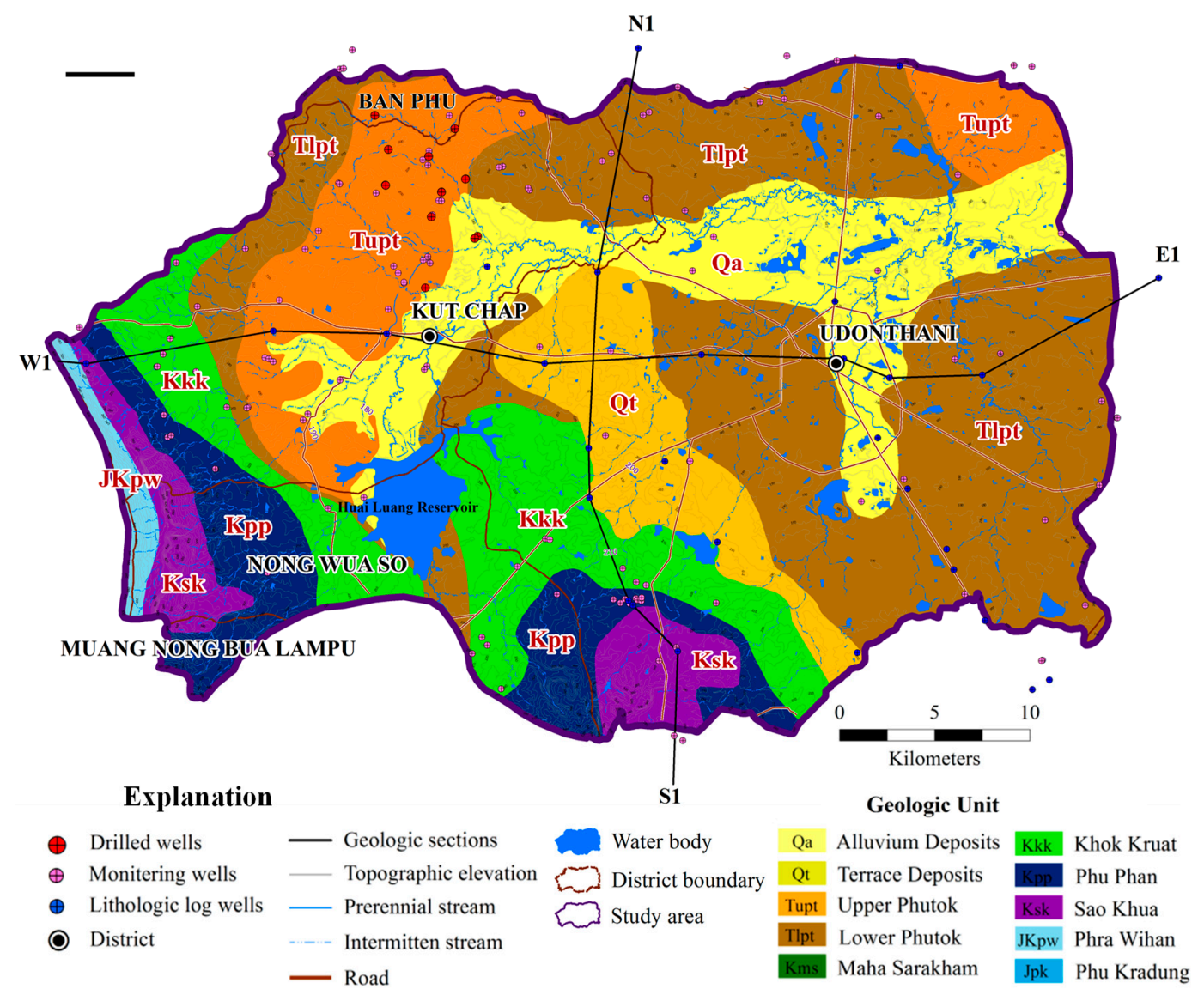

(a)
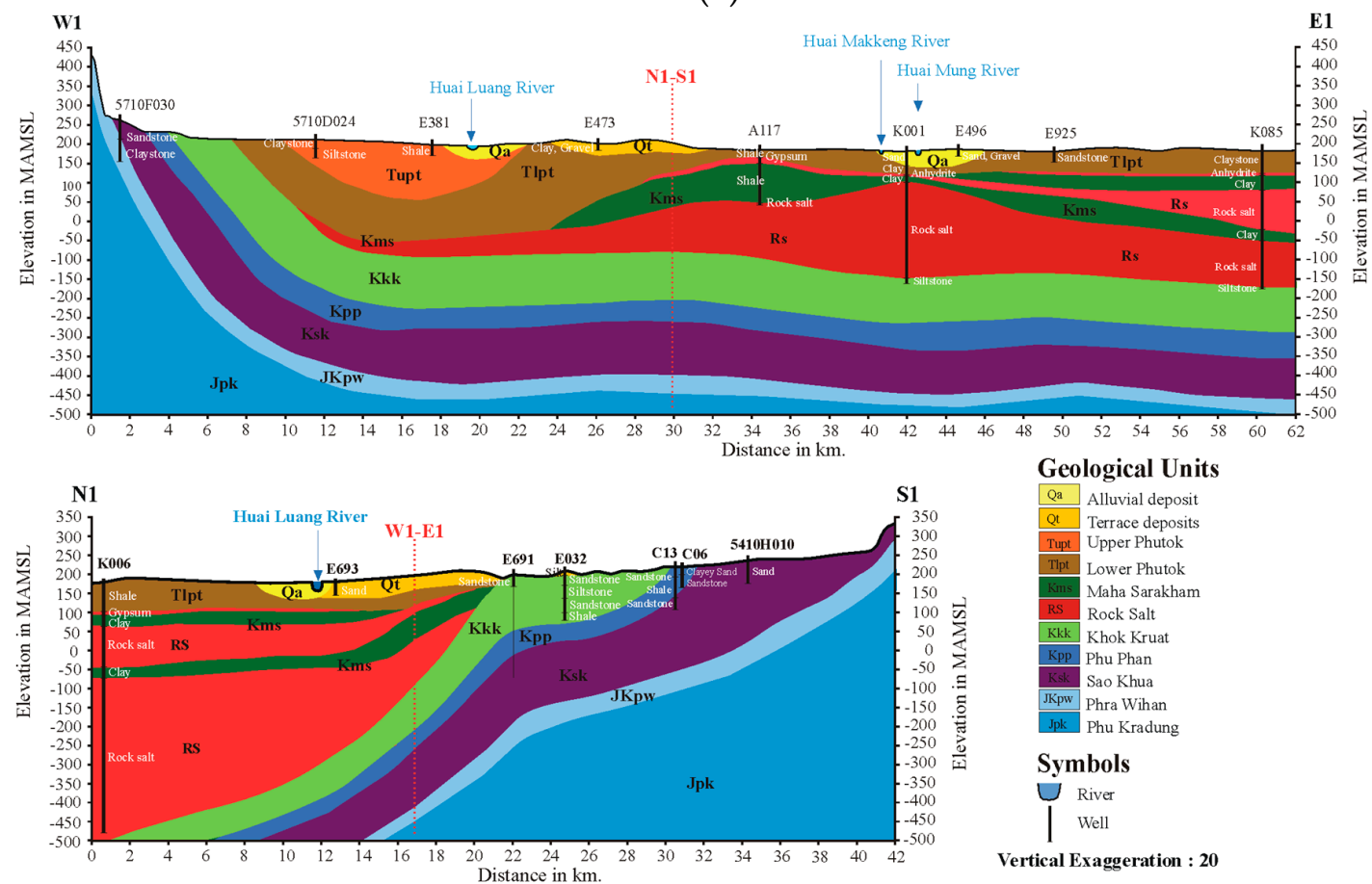

(b)

Figure 3. Geologic map and cross sections. (a) geologic map of CHLB; and (b) geologic cross sections along lines W1-E1 and N1-S1. 


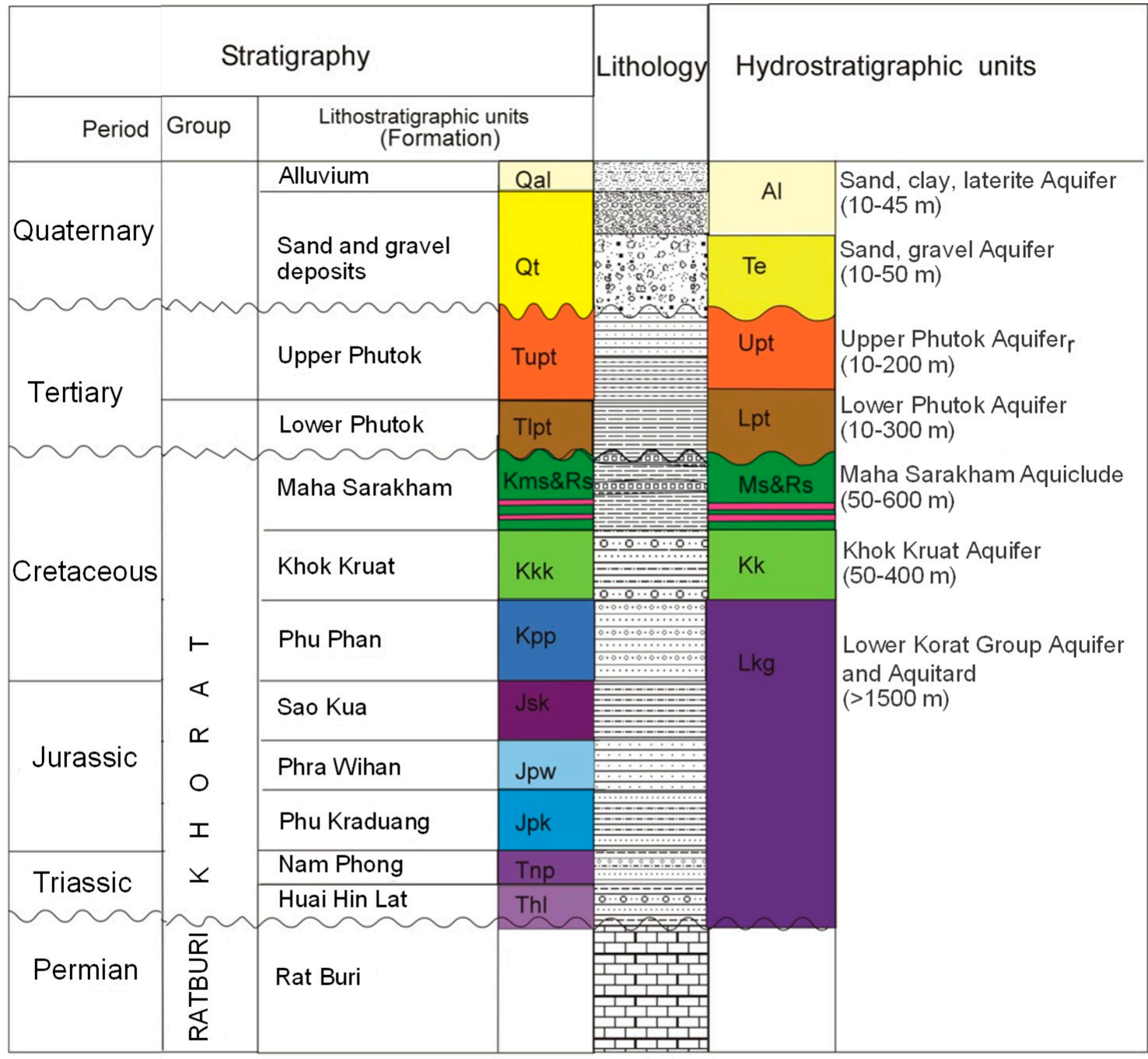

\section{Symbols}

Clay, silt and sand
Sand
Laterite, sand and silt
Sand and gravel

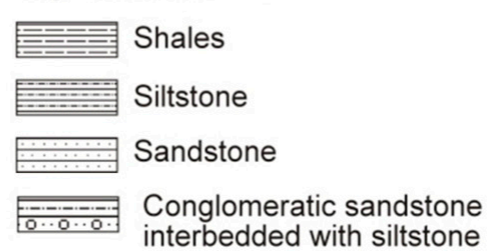

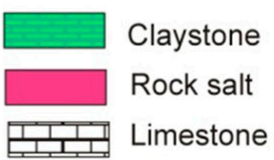

Geologic Symbol interbedded with siltstone $\sim$ Unconformity

Figure 4. Hydrostratigraphic units of the CHLB (modified from [39]).

Groundwater level, measured in 152 wells in 2014, shows that the water level varies from $4.6 \mathrm{~m}$ above the ground surface to $21.6 \mathrm{~m}$ below the ground surface. Groundwater flow primarily occurs in the lowlands of the Huai Luang floodplain, whereas deep water was found in the south and west, where the surface elevation is relatively high. The equipotential lines and groundwater flow directions measured during 2014 are depicted in Figure 5. Regional hydraulic heads in sandstone and siltstone of the Phutok, Khok Kruat, and the Lower Khorat Group aquifers range from 160 to 350 MAMSL. Generally, groundwater recharges to the aquifers in the west, south, and local recharge hilly areas in the north (recharge areas), whereas the discharge areas are normally found along the Huai Luang River floodplain and the central part of CHLB. The regional groundwater flows towards the north and northeast and discharges into the Huai Luang River. 


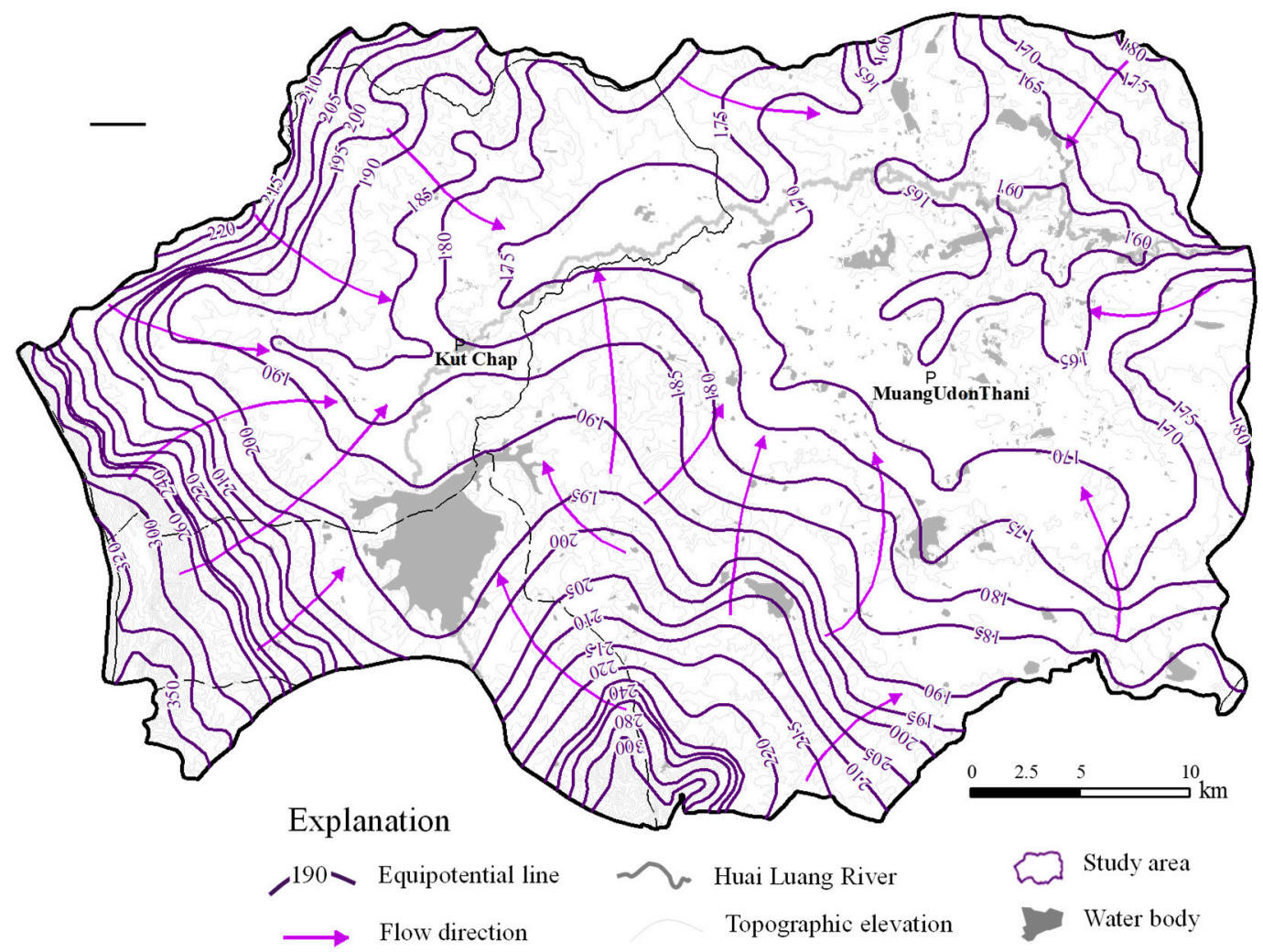

Figure 5. Regional groundwater flow of the CHLB.

\subsection{Groundwater Quality}

The principal chemical characteristics of groundwater in the CHLB aquifer system are elevated total dissolved solids (TDS) and chloride, both signatures of brackish and saline water derived from the Maha Sarakham rock salts. TDS in groundwater varies from less than 60 to 55,800 mg/L, measured at 189 monitoring wells in 2014-2015, as shown in Figure 6. Groundwater samples were taken from all hydrogeologic units, with $52 \%$ of samples taken from the Upper and Lower Phutok aquifers and $21 \%$ and $20 \%$ of samples taken from Khok Kruat and Lower Khorat Group aquifers, respectively. The samples from Maha Sarakham unit were taken only from 12 drilled wells and all the rest of the wells are saline groundwater. Approximately $75 \%$ of samples contain TDS concentration less than $1000 \mathrm{mg} / \mathrm{L}$, which is the upper limit recommended for drinking water and defined as freshwater [40-42], and about $7 \%$ of samples contain TDS exceeding 10,000 mg/L. The cross section of Figure 6 shows that high TDS or salinity varies with depth and is found in the lowlands in the central part of the study area along the Huai Luang River or discharge area and upward of groundwater flowing areas.

Groundwater samples from 30 wells around the basin were collected in 2014 for analyzing concentrations of major cations $\left(\mathrm{Na}^{+}, \mathrm{K}^{+}, \mathrm{Ca}^{2+}\right.$, and $\left.\mathrm{Mg}^{2+}\right)$, and anions $\left(\mathrm{Cl}^{-}, \mathrm{HCO}_{3}{ }^{-}, \mathrm{SO}_{4}{ }^{2-}\right.$, and $\mathrm{NO}_{3}{ }^{-}$). Major cations and anions of all water samples were plotted in Piper Diagram. Hydrochemical facies were classified based on Cotanont [43], as shown in Figure 7. The groundwater types can be classified into eight types: $\mathrm{Ca}-\mathrm{HCO}_{3}, \mathrm{Ca}-\mathrm{Na}-\mathrm{HCO}_{3}, \mathrm{Na}-\mathrm{HCO}_{3}, \mathrm{Ca}-\mathrm{HCO}_{3}-\mathrm{Cl}$, $\mathrm{Ca}-\mathrm{Na}-\mathrm{HCO}_{3}-\mathrm{Cl}, \mathrm{Na}-\mathrm{HCO}_{3}-\mathrm{Cl}, \mathrm{Ca}-\mathrm{Na}-\mathrm{Cl}$, and $\mathrm{Na}-\mathrm{Cl}$. $\mathrm{Ca}-\mathrm{HCO}_{3}$ and $\mathrm{Na}-\mathrm{HCO}_{3}$ types are found in the uplands and hilly areas or recharge areas. $\mathrm{Ca}-\mathrm{HCO}_{3}-\mathrm{Cl}, \mathrm{Ca}-\mathrm{Na}-\mathrm{HCO}_{3}-\mathrm{Cl}, \mathrm{Na}-\mathrm{HCO}_{3}-\mathrm{Cl}$, and $\mathrm{Ca}-\mathrm{Na}-\mathrm{Cl}$ types are found between recharge and discharge areas or at the midline. $\mathrm{Na}-\mathrm{Cl}$ type is found in areas with a TDS of greater than $1000 \mathrm{mg} / \mathrm{L}$ and is normally located in the discharge area. 


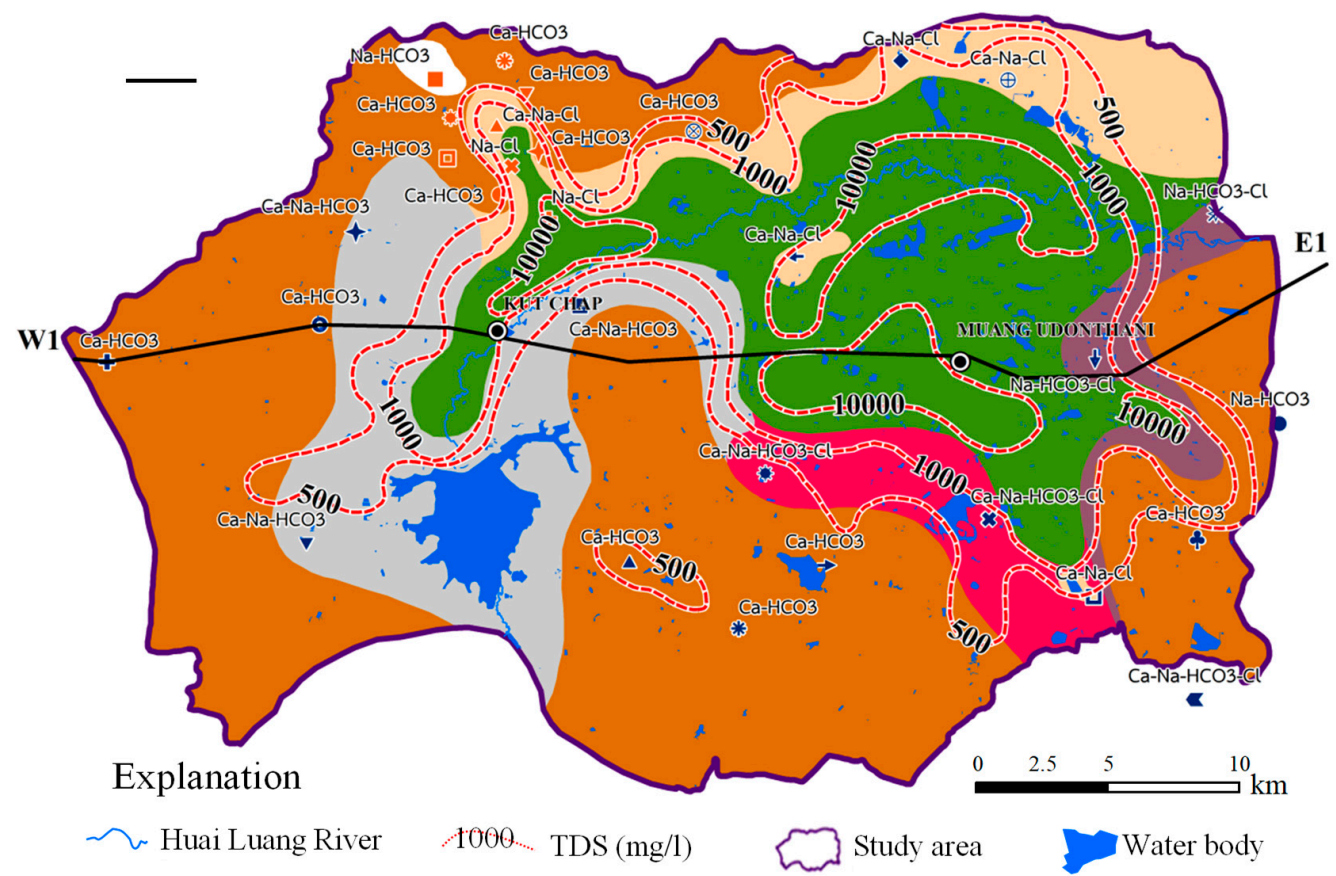

(a)

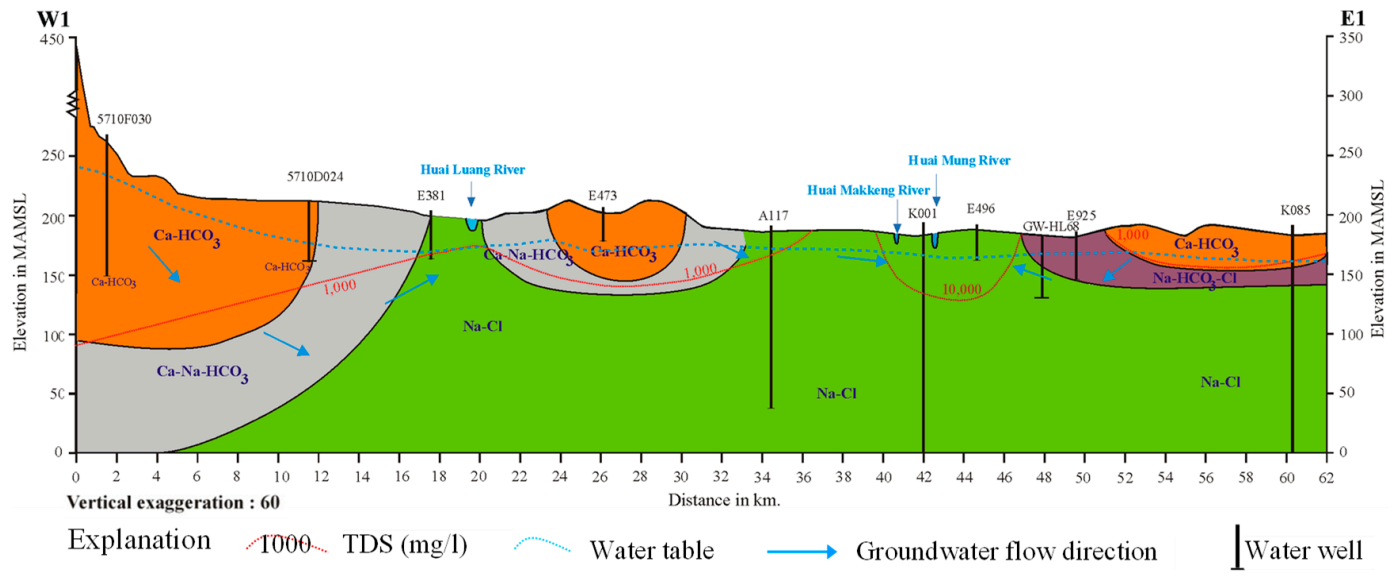

(b)
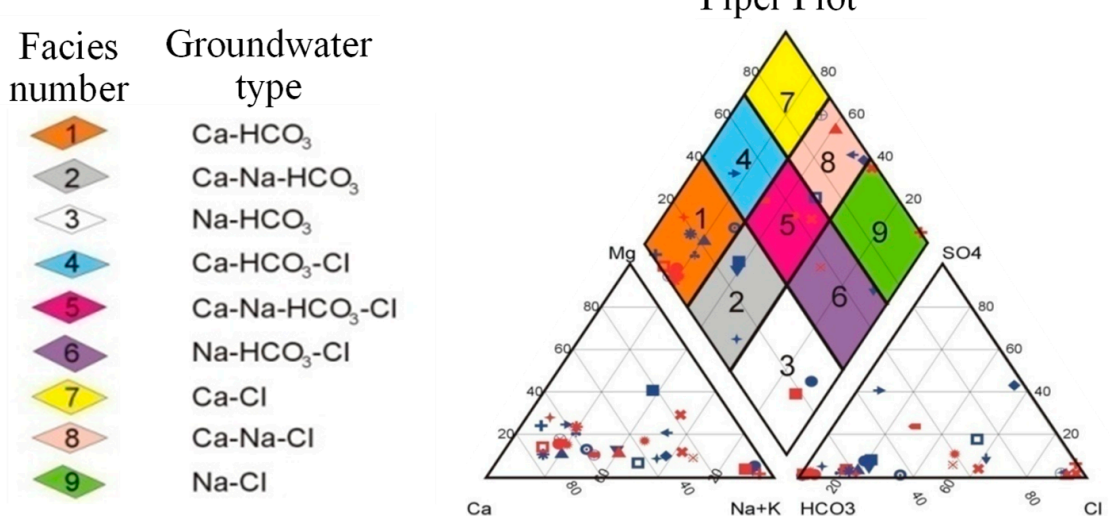

(c)

Figure 6. Groundwater type of CHLB. (a) Hydrogeochemical facies map; (b) Hydrogeochemical facies cross section along line W1 to E1; (c) Piper plot diagram of groundwater samples. 


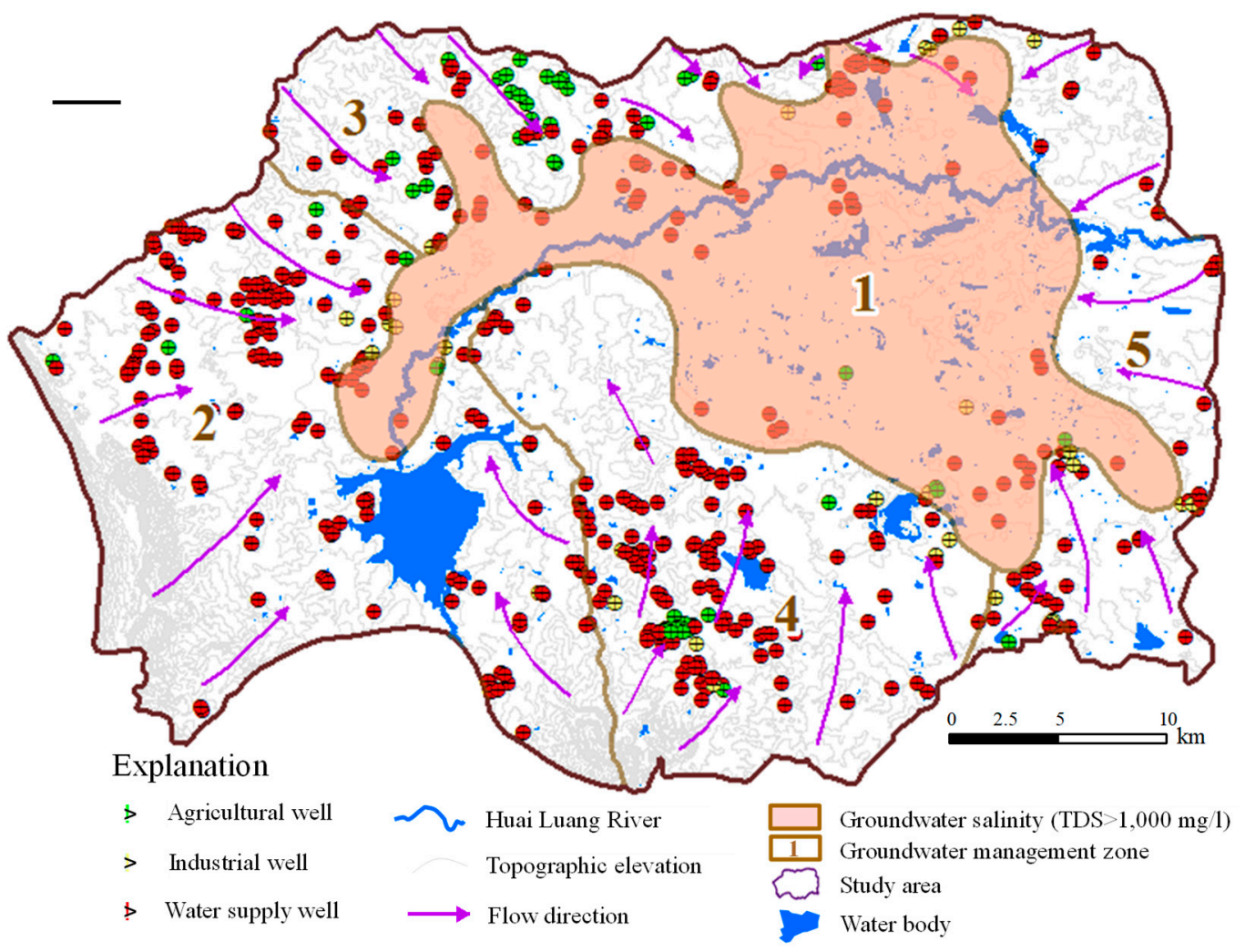

Figure 7. Location of groundwater wells and groundwater management zones.

\subsection{Groundwater Abstraction}

There are about 650 water wells that are used for domestic and water supply, agricultural, and industrial purposes. Water wells were drilled to several hydrostratigraphic units with depths ranging from 20 to $122 \mathrm{~m}$ below the ground surface. Most of them have been extracting groundwater from the Lower and Upper Phutok, and Khok Kruat aquifers. Water censuses are mainly being used to assess the groundwater in rural areas. Water usage for both surface water and groundwater was investigated by questionnaires. Information on sources of water, amount of water usage, activities, and water well data was gathered by questioning village leaders from 47 villages in 12 subdistricts of the CHLB. The water use investigation indicated that the total annual groundwater use in the basin was about $6,758,606 \mathrm{~m}^{3}$, of which water supply, agricultural and industrial sectors use $75 \%, 20 \%$, and $5 \%$, respectively.

For better estimating the sustainable yield and future planning and implementing groundwater development control measures, the spatial distribution of groundwater management zones was divided in this study. The groundwater management zones were divided into five zones based on their concentrations of TDS and groundwater flow systems. The high salinity zone or zone 1, which is the high TDS zone, was bounded by the area with TDS concentration higher than $1000 \mathrm{mg} / \mathrm{L}$, whereas other groundwater management zones were bounded based on groundwater flow systems in accordance with the flow directions and sources of their recharge areas. Groundwater management zones 2 to 5 were divided from the area outside zone 1 into four zones, as shown in Figure 7. Most of the groundwater is abstracted from zones 2 and 4, and groundwater level withdrawal was intensively observed. Zones 3 and 5 are at risk from groundwater salinity upconing and a decline in water level due to being located in a discharge area where the rock salt of the Maha Sarakham formation is shallow, and the groundwater pumping rate is relatively high. Groundwater pumping within zones 2 and 3 accounted for about 34\% and 33\% of groundwater usage, respectively, generally extracted from the Khok Kruat, Lower Khorat Group, and Upper Phutok aquifers (Figure 8a). Groundwater in zones 1-3 was generally extracted from the Lower Phutok aquifer, which is underlain by rock salt of the 
Maha Sarakham formation. Domestic and water supply was the main purpose for almost every zone, except zone 3 (Figure 8b). Groundwater usage for agriculture is relatively high in zones 3 and 4, due to the Department of Groundwater Resources (DGR) offering agricultural wells for groups of farmers, while groundwater for the industrial and business sectors was mainly extracted from zones 1 and 5 .

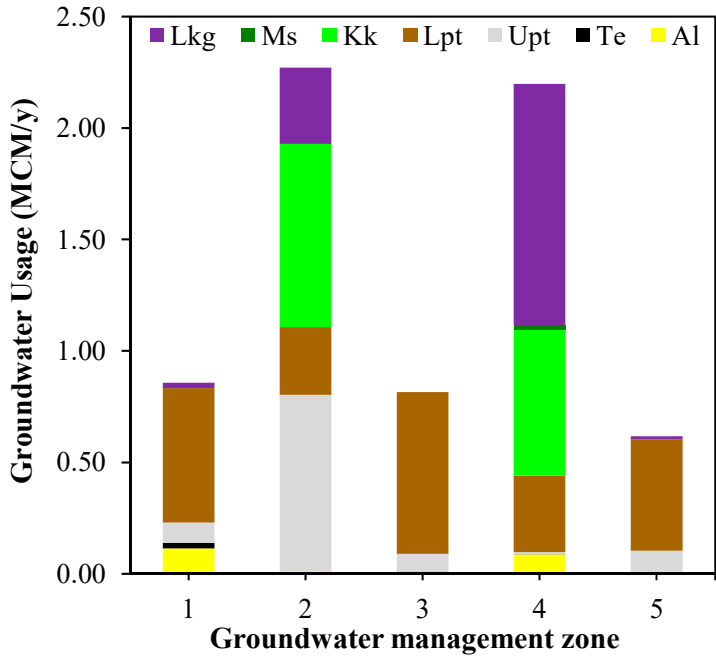

(a)

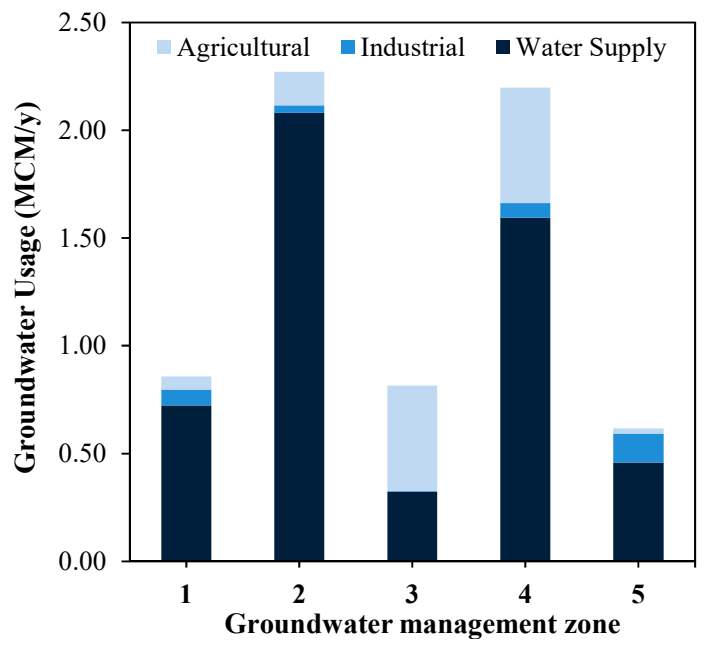

(b)

Figure 8. Comparison of groundwater usages and groundwater management zones for (a) hydrostratigraphic units and (b) types of groundwater usage.

\section{Numerical Groundwater Model}

Groundwater flow, saline water transport, water budget, and the sustainable groundwater yield in the CHLB aquifer system were simulated using a SEAWAT (version 4) model [44]. SEAWAT is a finite difference code that simulates variable density flow in three dimensions by combining the flow equations in the USGS Modular Three-Dimensional Finite-Difference Ground-Water Flow Model was released on July 20, 2000, or MODFLOW-2000 [45] with the solute transport equations in Modular Three-Dimensional Multispecies Transport Model or MT3DMS [46] into a single program coupling the flow and solute transport solutions.

\subsection{Hydrogeological Conceptual Model of CHLB Aquifers}

The configuration of the CHLB aquifers is an elongated shape that covers an area of about $1529 \mathrm{~km}^{2}$. The basin is enclosed by mountain ridges and hills in the west, south, and north, and the Huai Luang River cuts through the whole of the basin area and flows east between the mountains to the west and north, as shown in Figure 9. The groundwater flow in the aquifer system mainly converges from the west, south, and north towards the plains in the middle of the basin. The CHLB aquifer domain is conceptualized based on the geological and the hydrogeological components depicted in Figure 9. Seven hydrostratigraphic units (aquifers and aquitards) were assigned with several hydraulic properties, as indicated in Table 1. These parameters are significant properties of the units that were used as initial inputs in the numerical model. The sand, clay, and gravel of $\mathrm{Al}$ and Te units have a thickness of 10-40 m, the siltstone and sandstone aquifer of the Upt unit has a thickness of 30-200 m, the claystone of the Lpt unit has a thickness of 10-280 that is underlain by the rock salt layers of the Ms unit, and the siltstone and sandstone aquifer of Kk unit and Lkg unit has a thickness of 430 to $700 \mathrm{~m}$. Various types of boundary conditions are used to characterize key features of the groundwater system. A no-flow boundary condition was applied at all layers at the lateral boundaries to coincide with the presumed groundwater divides in all directions of the basin, as well as the bottom boundary. Huai Luang Reservoir, Huai Luang River, and its tributary were assigned to river boundary conditions. 
Net recharge was evaluated by the HELP3 model [47], which applied to the top of the active portion of the top model layer by zone.

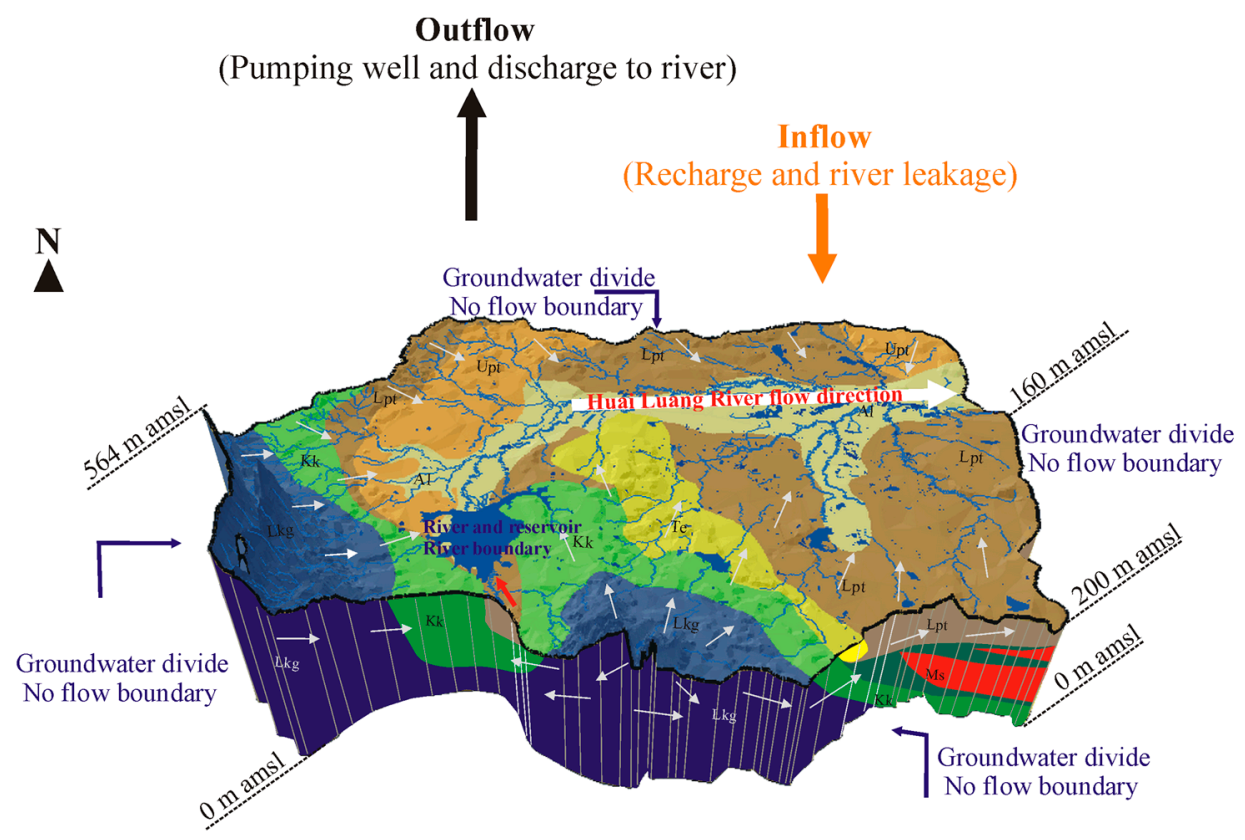

Figure 9. Boundary conditions of the hydrogeological conceptual model of CHLB aquifers system (model A).

The accuracy of the groundwater flow model is limited by the hydrogeological conceptual model validity, the numerical flow model design, and the input parameters' accuracy. Specific assumptions and simplifications for the conceptual model may lead to predictive modeling errors, which can lead to errors in policy or design for management. Policy and design decisions can be more robust if they are based on an explicit consideration of model conceptual uncertainty, which groundwater management studies are beginning to do $[4,9,48]$. In this study, four plausible alternative hydrogeological conceptual models (models A, B, C, and D) were constructed to simulate how the uncertainty associated with model geometry and boundary conditions influences the modeling results. The summary of alternative conceptual models' conditions is presented in Table 2.

The initial model (model A) was constructed under a conceptual model as shown in Figure 10. The motivation was to estimate the reliability of model predictions and to better clarify the potential impact of conceptual model assumptions. Three other plausible alternative hydrogeological characteristics were constructed by adding to the model A assumption. Uncertainties associated with the boundary conditions and hydrogeological conditions were simulated to investigate the effects on the results of long-term water-level prediction and sustainable yield under future climate change.

Table 2. Comparison of alternative conceptual models' conditions.

\begin{tabular}{lllll}
\hline Model & General Design & Model Layers & No-flow Boundary & General Head Boundary (GHBs) \\
\hline A & $\begin{array}{l}\text { The initial model, } \\
\text { constructed under } \\
\text { the conceptual } \\
\text { model of Figure 10. }\end{array}$ & $\begin{array}{l}\text { Seven hydrostratigraphic } \\
\text { units }\end{array}$ & $\begin{array}{l}\text { All layers at the edge of boundary of } \\
\text { study area and the bottom of model }\end{array}$ & - \\
B & Same as model A & $\begin{array}{l}\text { The rock salt layers are } \\
\text { shallower than model A for } \\
\text { at least 1 layer }\end{array}$ & $\begin{array}{l}\text { Same as model A } \\
\text { The bottom of model and all layer at } \\
\text { the edge of boundary of study area, } \\
\text { excepted where the study area } \\
\text { boundary cut off Huai Luang River at } \\
\text { the east and southwest } \\
\text { Same as model C }\end{array}$ & $\begin{array}{l}\text { All layers at east and southwest, } \\
\text { where the study area boundary cut } \\
\text { off Huang River }\end{array}$ \\
C & Same as model A & Same as model A & Same as model A & Same as model C \\
\hline
\end{tabular}




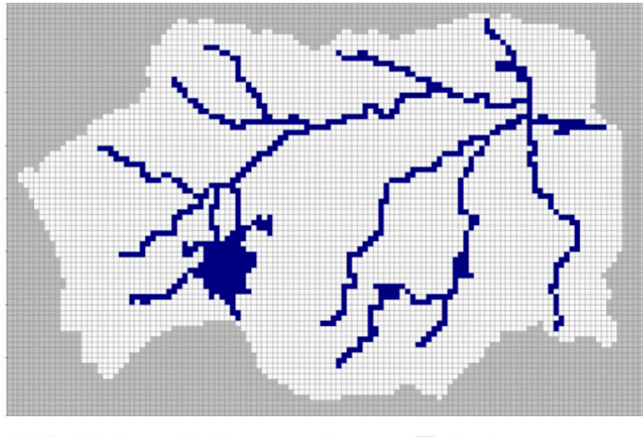

Explanation
River boundary

(a)

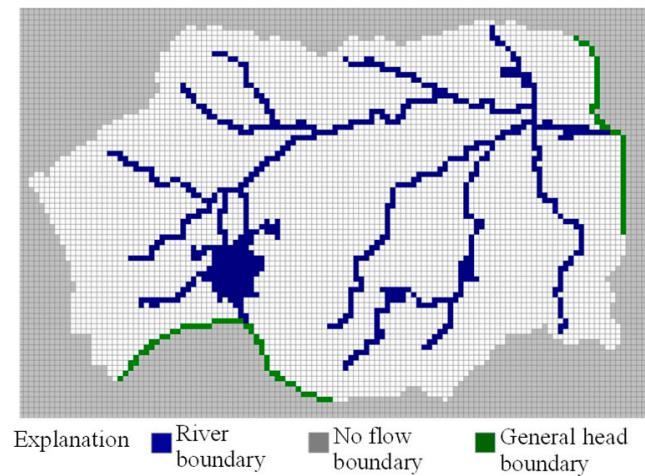

(b)

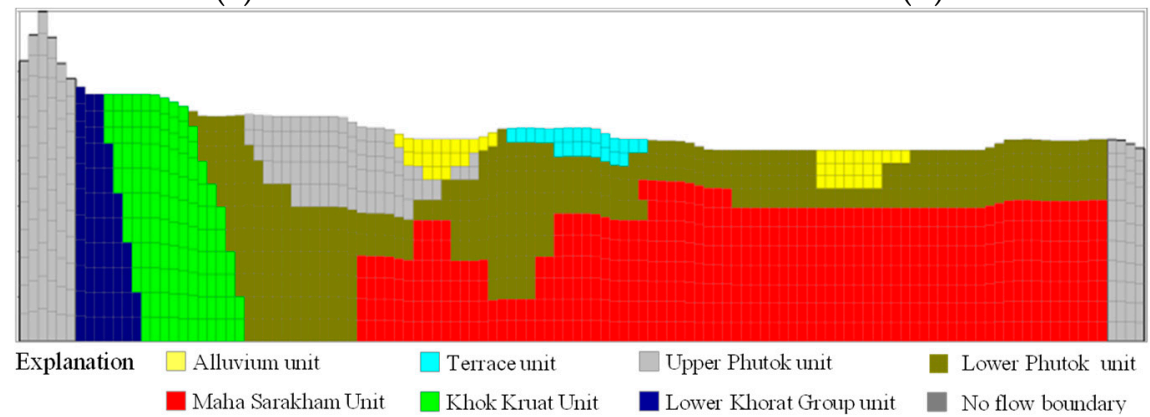

(c)

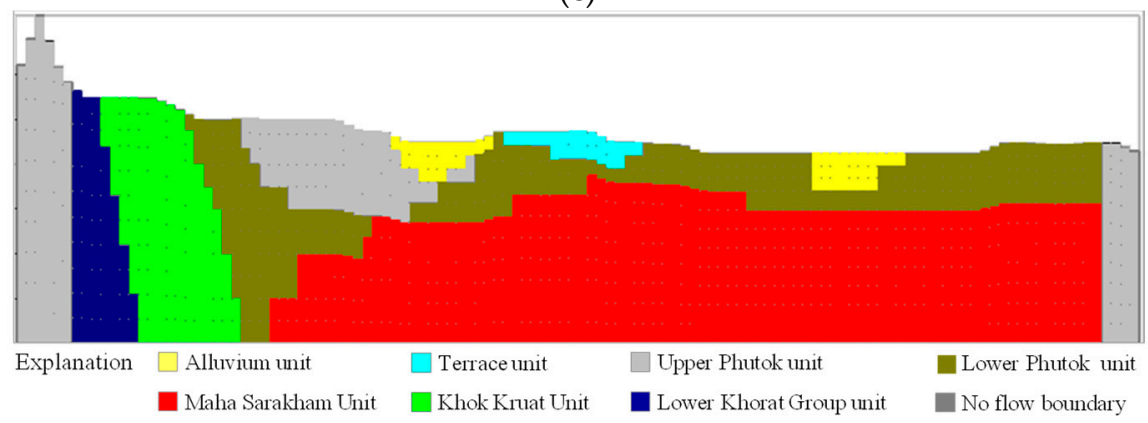

(d)

Figure 10. Grid design and boundary conditions under alternative hydrogeological conceptual models. (a) Lateral flow boundary condition of models A and B; (b) Lateral flow boundary condition of models C and D; (c) Aquifer properties zones of models A and C; (d) Aquifer properties zones of models B and $\mathrm{D}$.

Model B was constructed by varying the dimensions, or depths and thicknesses, of the rock salt formation, which is different from the initial model. From 12 potash exploration wells that were drilled through the depths of 130-670 m below the ground surface, only seven wells drilled through rock salt. Therefore, uncertainties about the depth of rock salt and its configuration may affect the hydraulic conductivity, dispersion coefficient, and other relative parameters and then change the groundwater flow, salinity, and sustainable yield of the basin from model A. In model B, the rock salt underneath the basin was assumed to be shallower than in model A.

In model $\mathrm{C}$, general head boundary conditions (GHBs) were assigned instead of the no-flow conditions at the lateral boundaries located in the east and southwest, where the Huai Luang River is located. According to the boundary of the study area is part of the Huai Luang River Basin, which has boundaries at the east and southwest where the study area is cut off from the whole basin. These areas can be considered to allow groundwater flow in and out through the study area because of the possibility of fluctuation of the aquifer head of the inner and outer bounds under seasonal change. 
Model D was constructed by adding a combination of layers of rock salt (model B) and GHBs at the east and southwest of the basin (model C).

\subsection{Groundwater Model Design}

The groundwater domain encloses an area of $40 \times 60 \mathrm{~km}$ and $450 \mathrm{~m}$ in depth. The model domain is a uniform square grid comprising a grid of $500 \times 500 \mathrm{~m}$, as shown in Figure 11. A digital elevation model was used to define the upper surface of the aquifer system. The thickness of model was separated into 11 layers 10-40 m thick, between the elevations of 0-564 MAMSL. The model layer thickness varies with changes in topography; upper layers (layers 1 to 3) were assigned to be 10-15 m thick, while the thicknesses of model layers 4 to 11 is about $25-40 \mathrm{~m}$. The groundwater domain was designed using physical boundaries and a conceptual model of the basin. For models A and $\mathrm{B}$, the boundaries of the study area were applied to a no-flow boundary condition or inactive cell in all layers and all directions (Figure 10a). A no-flow boundary condition in models C and D was applied at the rim of the study area with presumed groundwater divides in the mountain and hill ridges of west, south, and north. Huai Luang River, cut off from the whole basin at the east and southwest, was applied to general head boundaries in all layers (Figure 10b). The volume of general head boundaries assigned for Huai Luang River was collected from hydrological stations Kh.103 and Kh.53. The boundaries and geometry of aquifer properties such as hydraulic conductivity, storage coefficients, porosity and dispersion coefficient, were assigned to the groundwater model as the value in Table 1. In models A and C, the shapes of aquifer property zones within the model layer are based on geology, lithology, and conceptual models of the flow system (Figure 10c). The shape of rock salt in models B and D was constructed to be shallower than model A-about one layer or 10-20 m in areas that do not have deep wells or evidence that confirms the depth of the rock salt (Figure 10d). The uppermost layer was treated as an unconfined aquifer, while the others were treated as confined aquifers; the storage coefficient was assigned as the specific yield for unconfined and storativity for confined aquifers.

Groundwater recharge rates depend on the rainfall intensity, temperature, other weather conditions, slope, soil, and ground surface cover. Therefore, climate change can affect groundwater recharge and subsequently groundwater storage, flow, and saline groundwater distribution. The recharge rates were discretized into nine zones based on land use, soil types, and topographic slopes, as shown in Figure 11. Net recharge rates for each zone were estimated using a quasi-two-dimensional model of the Hydrologic Evaluation of Landfill Performance version 3 (HELP3) computer program [47], which was used to estimate the impact of climate change on groundwater recharge worldwide (e.g., [20,49,50]). The HELP3 model is a deterministic water routing model for computing water balances and simulates the daily movement of water into the ground. The input data on daily climate, soil properties, land cover, and plant growing season, and spatial data at the study area, are required. The soil properties and soil profiles in CHLB surveyed in 2015 included soil texture, total capacity, field capacity, saturated moisture content, dry bulk density, and saturated hydraulic conductivity, which were assigned as the initial input parameters for applying the HELP3 model. The layers of soil profile from the top to $2 \mathrm{~m}$ below the ground surface were assigned into 2-4 layers based on the soil texture and properties in each recharge zone. The net recharge rates in each zone are used as inputs for the SEAWAT model in order to simulate groundwater levels, flow patterns, and salinity distributions (Figure 11).

Pumping from wells was simulated using MODFLOW's well package. The locations of all pumping wells in the CHLB are presented in Figure 12a. Volumes of groundwater discharge indicate that more than $60 \%$ of the groundwater pumped from wells screened in model layers 3-4 (Figure 12b) is in the hydrogeologic units of Lpt and Kk. 


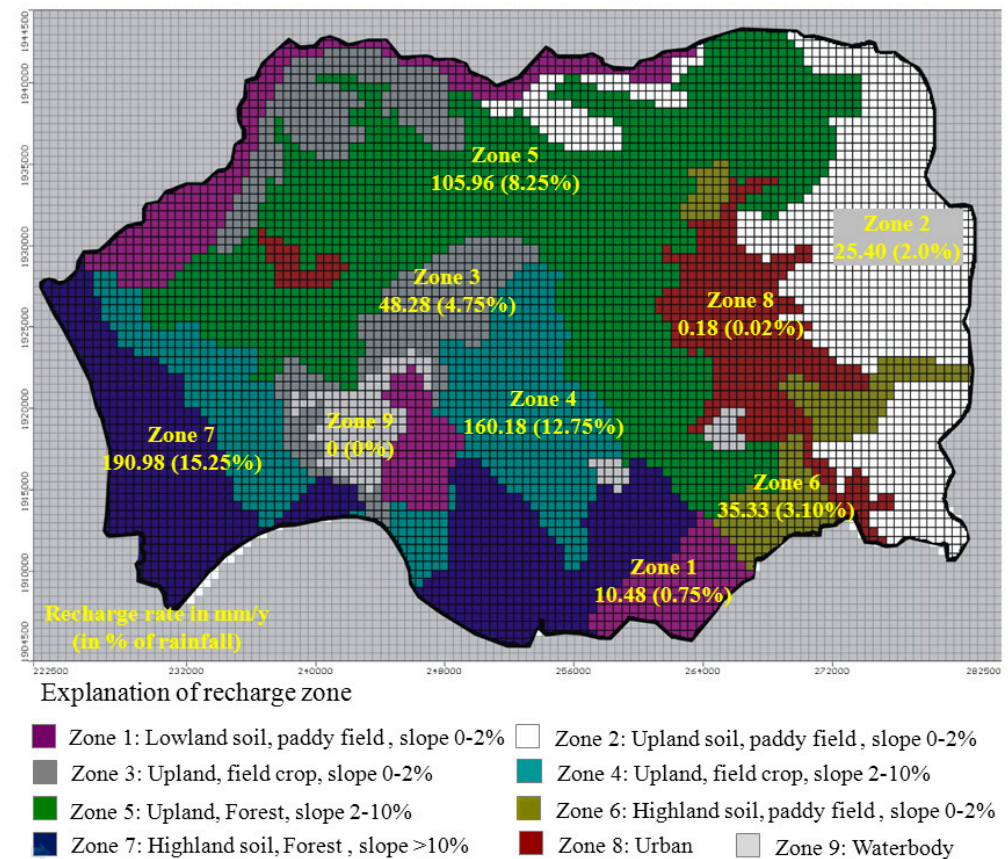

Figure 11. Recharge zones, their properties for the HELP3 model, and recharge rates for SEAWAT models.

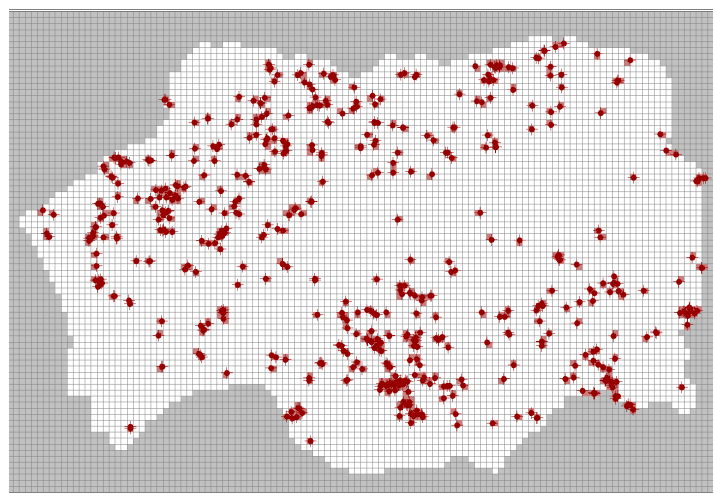

(a)

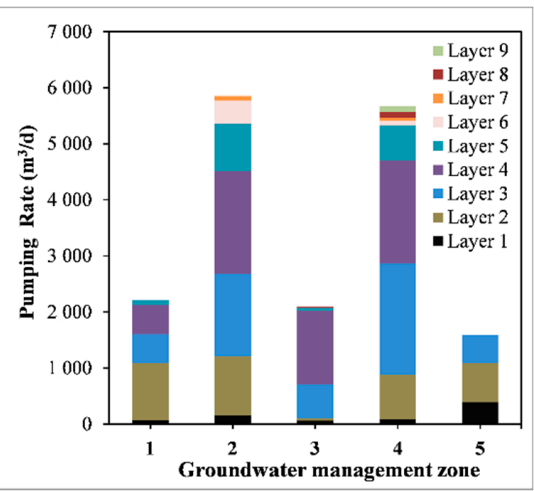

(b)

Figure 12. Locations of pumping well (a) and pumping rates in groundwater management zones from model layers (b).

\subsection{Model Calibration and Sensitivity Analysis}

\subsubsection{Model Calibration}

The groundwater model calibration was carried out to assure reasonable results and model accuracy. The initial model (model A) was calibrated by manual trial and error method to minimize the difference between simulated and observed hydraulic heads for groundwater flow, and to compare the simulated and observed salinity values (TDS) in the solute transport model. The transient model during the period from 2010 to 2015 was simulated with the models HELP3 and SEAWAT. Hydraulic heads and salinity in 89 observation wells were monitored from September 2014 to December 2015 and selected as calibrated data. Horizontal and vertical hydraulic conductivities were changed during the calibration process, as well as the groundwater recharge rates. Recharge rates are the most sensitive parameter of a groundwater flow system, while dispersivity is the most sensitive parameter of a groundwater solute transport [9]. Accordingly, these parameters of aquifer properties, including the horizontal and vertical hydraulic conductivities, specific storage, specific yield, dispersion coefficient, and porosity of each hydrogeological unit, can be adjusted to meet the calibration targets. The uniform 
anisotropy ratio between horizontal and vertical hydraulic conductivities of 1:10 was not adjusted during the calibration process. The calibrated value of aquifer properties obtained is presented in Table 3. The groundwater recharge model was calibrated under the SEAWAT model by varying the annual average recharge rates as a percentage of precipitation. Once it was calibrated, relative recharge rates were fixed in each zone, and the calibrated recharge rates from the SEAWAT model were used to calibrate the input parameters of the HELP3 model. Recharge rates used in the HELP3 model were recalibrated by varying the properties of input parameters until the volume of annual recharge from HELP3 met the lump sum volume of recharge from the SEAWAT model. The calibrated HELP3 model was used to estimate the daily fluctuation of recharge rates and changes of climate in the future. The groundwater recharge rates vary from $0 \%$ to $15.25 \%$ of rainfall or 0 to $190.98 \mathrm{~mm} /$ year (Figure 11 ) and gradually increase from discharge areas to recharge areas. A high recharge rate was found in recharge zones 4, 5, and 7, which are located in the recharge areas, where there is a high infiltration rate of highland and upland soil and coverage of forest and field crop. A low recharge rate was found in lowland discharge areas, which have a low infiltration rate of fine-soil texture and are used as paddy fields.

Table 3. Hydraulic parameters used in simulations of groundwater flow and solute transport in the SEAWAT model.

\begin{tabular}{|c|c|c|c|c|c|c|c|}
\hline Hydrogeologic Units & $\mathrm{Kh}(\mathrm{m} / \mathrm{s})$ & $\mathrm{Kv}(\mathrm{m} / \mathrm{s})$ & Ss $\left(m^{-1}\right)$ & S or Sy $(-)$ & Eff.P (-) & Tot.P (-) & DI (m) \\
\hline Alluvium (Al) & $8.8 \times 10^{-6}$ & $8.8 \times 10^{-7}$ & $1.0 \times 10^{-2}$ & 0.30 & 0.35 & 0.40 & 500 \\
\hline Terrace Deposit (Te) & $2.1 \times 10^{-5}$ & $2.1 \times 10^{-6}$ & $8.0 \times 10^{-3}$ & 0.25 & 0.30 & 0.40 & 600 \\
\hline Upper phutok (Upt) & $2.0 \times 10^{-6}$ & $2.0 \times 10^{-7}$ & $3.0 \times 10^{-3}$ & 0.15 & 0.25 & 0.30 & 150 \\
\hline Lower phutok (Lpt) & $5.1 \times 10^{-6}$ & $5.1 \times 10^{-7}$ & $1.7 \times 10^{-3}$ & 0.17 & 0.22 & 0.31 & 70 \\
\hline Rock salt (RS) & $2.0 \times 10^{-14}$ & $2.0 \times 10^{-15}$ & $1.0 \times 10^{-5}$ & 0.01 & 0.02 & 0.10 & 50 \\
\hline Khok Kruat (Kk) & $9.5 \times 10^{-7}$ & $9.5 \times 10^{-8}$ & $5.0 \times 10^{-3}$ & 0.20 & 0.25 & 0.30 & 70 \\
\hline Lower Khorat Group (Lkg) & $7.7 \times 10^{-7}$ & $7.7 \times 10^{-8}$ & $2.0 \times 10^{-3}$ & 0.20 & 0.25 & 0.30 & 150 \\
\hline
\end{tabular}

Note: Horizontal hydraulic conductivity (Kh), Vertical hydraulic conductivity (Kv), Specific storage (Ss), Storativity (S), Specific yield (Sy), Effective Porosity (Eff.P), Total Porosity (Tot.P), Longitudinal dispersivity (DI).

The calibration performance was evaluated by visual and statistical comparison of the observed and simulated data. The groundwater levels and salinity, in terms of TDS between the observed versus the simulated, both groundwater level and TDS, were measured and the statistical results of root mean square error (RMS) and the normalized root mean square error (NRMS) were analyzed. Figure 13 presents a scatter plot of observed and simulated hydraulic head, and simulated TDS, with statistical values (2010-2015) for model A. The RMS and NRMS of the hydraulic head are $2.82 \mathrm{~m}$ and $3.03 \%$, and TDS are $529.39 \mathrm{mg} / \mathrm{L}$, and $1.35 \%$, respectively. In addition, all correlated points are well within the $95 \%$ confidence interval of the slope 45 degrees from linear regression. These statistical results confirm the well-calibrated model is in a reliable condition. The spatial distribution hydraulic head and TDS comparison between observed and simulated data of model A at the end of the model (2015) are shown in Figure 13. The pattern of the simulated hydraulic head and TDS were fit well to the observed values. In general, no apparent spatial patterns of error were discernible and the calibration is regarded as acceptable. For checking the validity of the model, the model was validated with 33 observation wells that had been monitored from 2010 to 2012 by [36]. The results of the statistical measurements of the calibration and validation period are presented in Table 4 .

Table 4. Model performance during calibration and validation.

\begin{tabular}{cccccccccc}
\hline \multirow{2}{*}{ Model State } & \multirow{2}{*}{ Parameter } & \multicolumn{2}{c}{ Model A } & \multicolumn{2}{c}{ Model B } & \multicolumn{2}{c}{ Model C } & Model D \\
\cline { 3 - 9 } & & RMS & NRMS & RMS & NRMS & RMS & NRMS & RMS & NRMS \\
\hline \multirow{2}{*}{ Calibration } & Hydraulic Head (m) & 2.28 & $3.03 \%$ & 3.05 & $3.29 \%$ & 2.84 & $3.06 \%$ & 3.51 & $3.78 \%$ \\
& TDS (mg/L) & 529.39 & $1.35 \%$ & 538.25 & $1.38 \%$ & 547.81 & $1.40 \%$ & 646.46 & $1.65 \%$ \\
Validation & Hydraulic Head (m) & 2.99 & $4.14 \%$ & 3.76 & $4.40 \%$ & 3.55 & $4.17 \%$ & 4.22 & $4.89 \%$ \\
& TDS (mg/L) & 444.35 & $3.22 \%$ & 453.21 & $3.25 \%$ & 462.77 & $3.27 \%$ & 561.42 & $3.52 \%$ \\
\hline
\end{tabular}




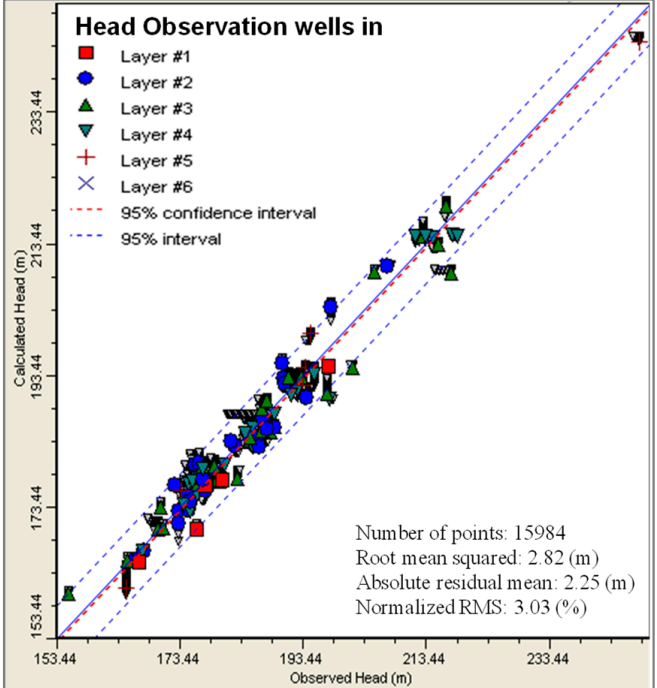

(a)

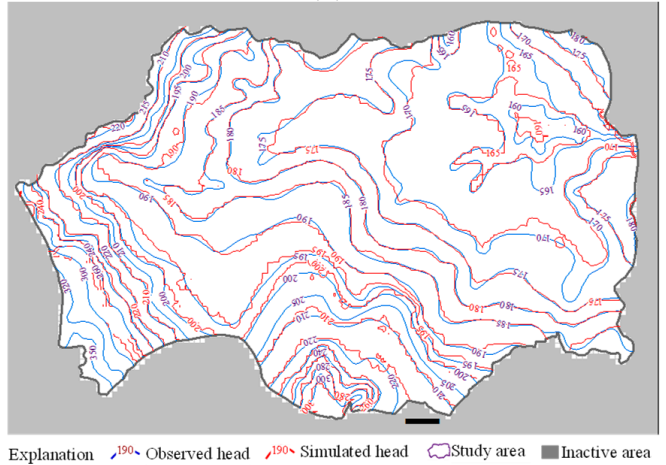

(c)

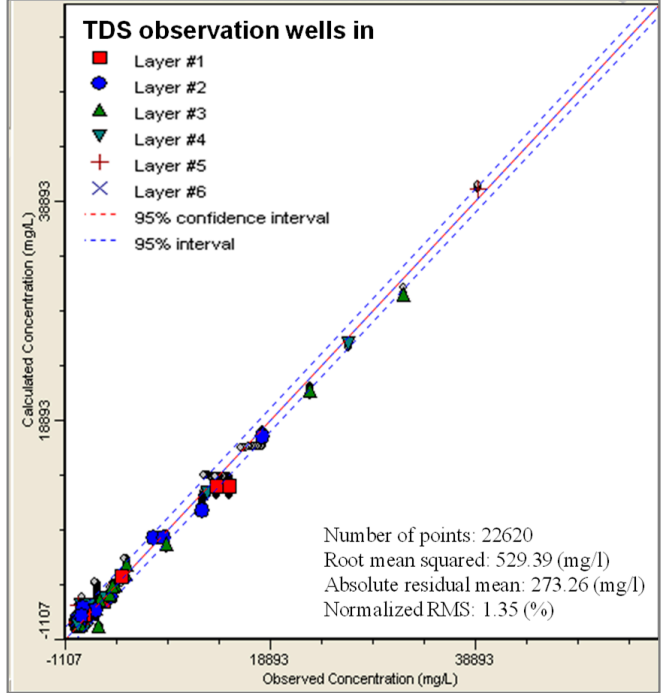

(b)

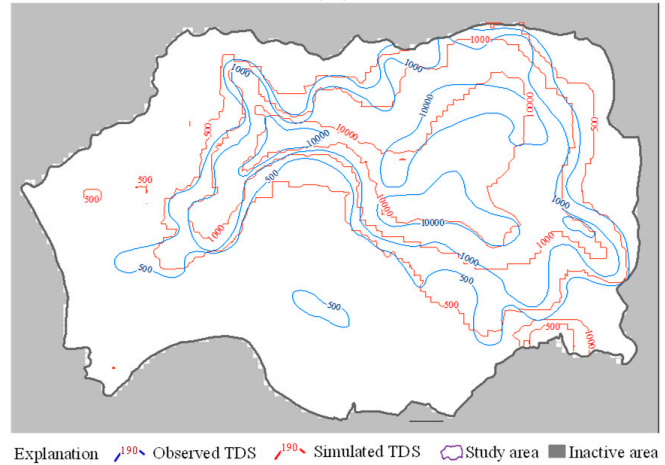

(d)

Figure 13. Observed versus simulated heads (a), simulated salinity (b) with the statistical results of model A and the comparison of observed and simulated of equipotential lines (c), and salinity (d) in layer 3 of model A at the end of 2015.

The alternative models (models B, C, and D) were calibrated and validated to the same set of observation wells following the same procedure as the initial model A. Table 4 shows the calibration statistics for these four models. The performances of these models were evaluated quantitatively and qualitatively, and, overall, they achieved similar levels of predictive accuracy.

\subsubsection{Model Sensitivity Analysis}

The overall sensitivity of the model predictions to each parameter is estimated by decreasing and increasing parameters at $25 \%$ and $50 \%$ of the calibrated parameters. The sensitivity analyses of the groundwater flow and salt transport model were carried out with the SEAWAT model. The recharge rates, hydraulic conductivity, and storage coefficients were considered to analyze the sensitivity of groundwater flow in terms of the absolute value of mean residual groundwater level. The results indicate that the recharge rates is one of the most sensitive parameters for the groundwater level, followed by hydraulic conductivity and storage coefficients [23]. Longitudinal dispersivity has been the most sensitive parameter for groundwater salinity simulation [23]. Groundwater level and salinity are affected more significantly by increasing parameters than by decreasing. For investigating the parameters that affected the recharge rate, the sensitivity of the recharge zone in the SEAWAT model was analyzed. The results indicated that the recharge rate at zone 2 is relatively most sensitive, followed by zones 1, 7, 4, 5, 3, 6, 8, and 9, as shown in Figure 14a. A sensitivity analysis of the recharge rate was carried out in order to explore the sensitivity of the input parameters in the HELP 
model including precipitation, temperature, leaf area index, evaporative zone depth, and surface slope. The results show that precipitation is the most sensitive parameter, followed by temperature (Figure 14b). The hydraulic conductivity and longitudinal dispersivity of hydrogeologic units were considered to be sensitive to groundwater level and salinity. The hydraulic conductivity of the Lower Phutok unit is the most sensitive, followed by Khok Kruat, Upper Phutok units, Lower Khorat Group, Alluvium, Maha Sarakham, and Terrace units (Figure 14c). The Lower Phutok unit was also most sensitive to groundwater salinity, followed by the Upper Phutok and Alluvium units. In contrast, the hydrogeologic unit underlain by the rock salt of Maha Sarakham indicated less sensitivity to groundwater salinity, as presented in Figure 14d.

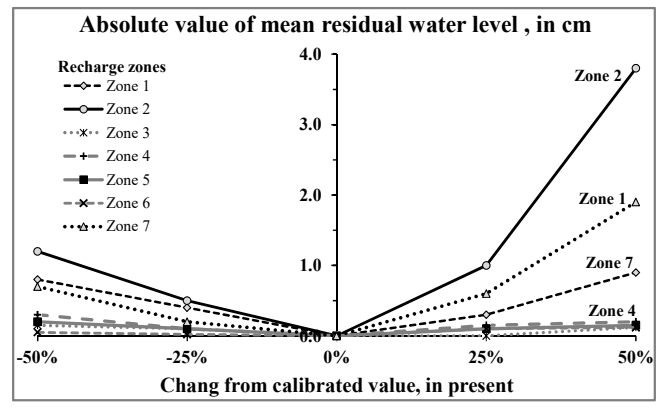

(a)

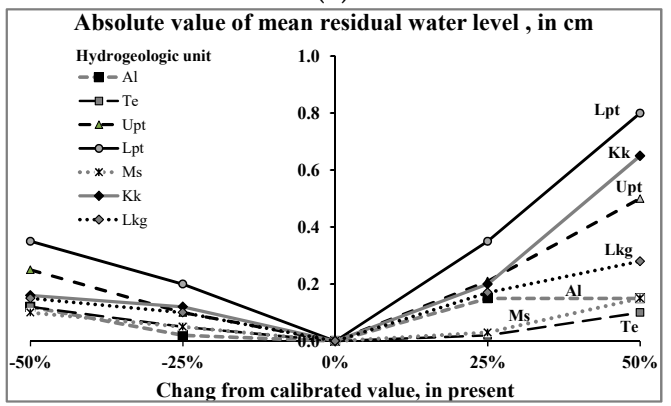

(c)

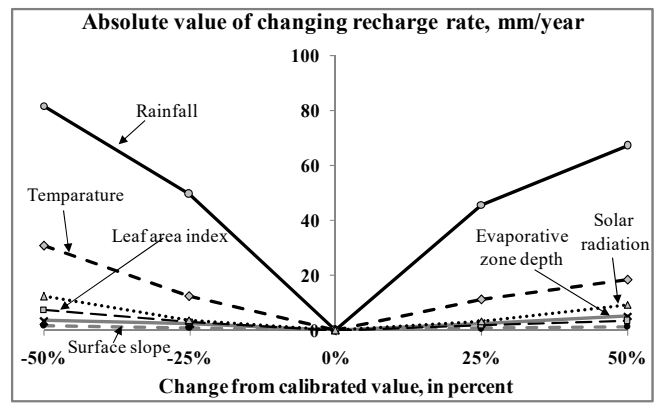

(b)

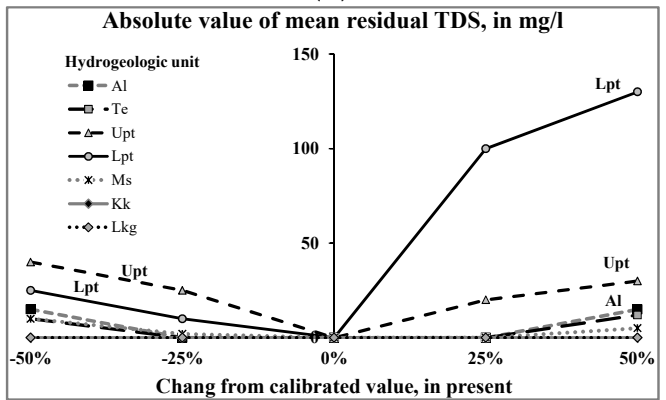

(d)

Figure 14. A sensitivity analysis of the calibrated models. (a) a sensitivity analysis of recharge rate of each zone of SEAWAT model; (b) a sensitivity analysis of recharge input parameter in the HELP model; (c) a sensitivity analysis of groundwater level of hydraulic conductivity of hydrogeologic unit; (d) a sensitivity analysis of groundwater salinity of longitudinal dispersivity of hydrogeologic unit.

\subsubsection{Model Aquifer Balance}

The aquifer balance of the calibrated model during the period of 2010-2015 was simulated under the four alternative hydrogeological conceptual models. The results show that the most inflow to the model is precipitation recharge $(94 \%)$ for all models. The remaining inflow is from the Huai Luang Reservoir, the Huai Luang River, and its tributaries, and flow into the basin from outside (GHBs) for models $\mathrm{C}$ and $\mathrm{D}$. About $28 \%$ of the discharge is being pumped from wells for all models. For models $\mathrm{A}$ and $\mathrm{B}$, about three-quarters of the total discharge is from baseflow to the river. The remainder is discharged to the river and flows out of the basin at GHBs for models $C$ and D. Figure 15 presents inflow and outflow for all alternative hydrogeological conceptual models.

The average annual water balance from all models shows that water inflow to the aquifers from groundwater recharge and river leakage and GHBs had been about 104.41-106.44 MCM/year, while the outflow from the aquifers through well abstraction, river leakage, and GHBs had been only 21.74-29.62 MCM/year. Inflow to the aquifers is greater than the water outflow from the aquifers at about 75.78-82.67 MCM/year. 


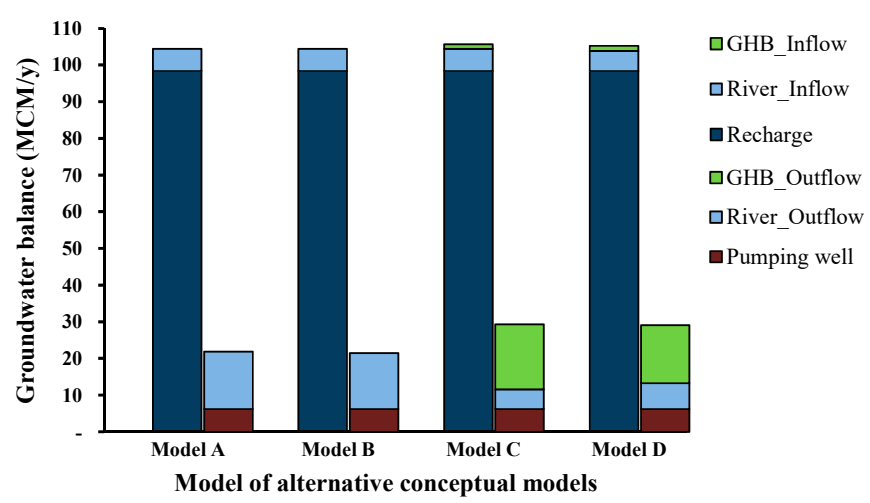

Figure 15. Inflow and outflow rates of aquifer balance in alternative hydrogeological conceptual models, 2010-2015.

\section{Future Climate Change}

In order to estimate groundwater flow and salinity distribution and assess the sustainable management of CHLB in the future, climate scenarios of the General Circulation Models (GCMs) from the IPCC for the Fifth Assessment Report (AR5) were considered. Several GCMs of AR5 have been widely used in Thailand, such as CNRM-CM5, MIROC-ESM, FGOAL-s2, MPI-ESM-LR, CESM1-BGC, CCSM4, CanESM2, HadGEM2-CC, and GFDL, and these can downscale the climate data using Gamma-Gamma transformation with an optimizing parameter method [32]. The downscaling of GCMs climate data to RCMs (Regional Climate Models) is a process for providing information at higher resolution $(10 \mathrm{~km})$ by removing any bias from the data for future climate projections [32]. Ten of RCMs were explored in order to select the representative future climate of the CHLB by using statistically analyzed records of temperature and precipitation data for the CHLB and from the RCMs in 2006-2015. The results of visual comparisons and statistical measurements (mean, median, standard deviation, and coefficient of determination) indicate that the CanESM2 shows the best correlation when compared to the others. Therefore, the second-generation Canadian Earth System Model (CanESM2) [51] was selected to represent the future climate of the CHLB for 2016-2045. The CanESM2 downscaled climate scenarios, which were used to investigate the impact of groundwater on the CHLB, had Representative Concentration Pathways (RCPs) of 2.6, 4.5, and 8.5. The RCPs were named according to the radiative forcing target level for 2100. The radiative forcing estimates are based on the forcing of greenhouse gases and other forcing agents. The three selected RCPs were considered to be representative of the literature, and included one mitigation scenario leading to a very low forcing level (RCP2.6), some medium stabilization scenarios (RCP4.5), and one very high baseline emission scenario (RCP8.5) [52].

The projected average monthly and annual temperatures and precipitation, from CanESM2 climate models for the years from 2016 to 2045, compared to the period 2006-2015, are presented in Table 5. The average annual temperatures of the models are higher than in 2006-2015 for all scenarios and almost every month (Figure 16a,b). In addition, a significant trend shows a gradual increase year after year. In a comparison among the three scenarios, the annual temperatures are not detected with a significant difference (Figure 16a), but it is noteworthy that the monthly temperatures of the RCP2.6 and the RCP4.5 are very close, while the monthly temperatures of the RCP8.5 were different from the others (Figure 16b). By the year 2045 the average annual temperatures are projected to increase by $1.6^{\circ} \mathrm{C}, 1.7^{\circ} \mathrm{C}$, and $2.07^{\circ} \mathrm{C}$ under the RCP2.6, RCP4.5, and RCP8.5 scenarios, respectively, compared to 2015 .

Projected annual rainfall is higher than in 2006-2015 for all scenarios (Table 5). In a comparison among the three scenarios, the annual precipitation indicates the strong fluctuation of extreme drought years in RCP2.6 scenario, while RCP8.5 scenario shows extreme heavy rainfall (Figure 16c). The RCP8.5 scenario projected the highest annual rainfall for almost every decade. The annual rainfall for all 
scenarios showed a gradually increasing trend between 2016-2025 and 2026-2035, and then a slight decrease in the last period (2036-2045) of the projection (Figure 16c). A comparison of these data during 2006-2015 indicates that average annual rainfall tends to increase by $5.85 \%, 6.94 \%$, and $11.26 \%$ under the RCP2.6, RCP4.5, and RCP8.5 scenarios, respectively.

Table 5. Future average monthly precipitation and temperature scenarios projected by climate models from 2016 to 2045.

\begin{tabular}{ccccccccccccccc}
\hline Climate & Scenarios & Jan & Feb & Mar & Apr & May & Jun & Jul & Aug & Sep & Oct & Nov & Dec & Annual \\
\hline \multirow{3}{*}{$\mathrm{T}\left({ }^{\circ} \mathrm{C}\right)$} & $2006-2015$ & 22.4 & 25.6 & 28.1 & 29.8 & 29.1 & 29.0 & 28.3 & 27.8 & 27.8 & 27.2 & 25.7 & 22.4 & 25.6 \\
& RCP2.6 & 25.0 & 27.5 & 30.4 & 31.9 & 31.1 & 30.3 & 30.6 & 30.1 & 29.4 & 28.0 & 25.3 & 23.7 & 28.6 \\
& RCP4.5 & 25.0 & 27.6 & 30.5 & 31.9 & 31.1 & 30.3 & 30.6 & 30.1 & 29.4 & 28.0 & 25.4 & 23.7 & 28.6 \\
& RCP8.5 & 25.6 & 27.7 & 30.2 & 32.1 & 31.0 & 30.5 & 31.1 & 30.5 & 29.5 & 27.8 & 25.8 & 23.6 & 28.8 \\
\hline \multirow{3}{*}{$\mathrm{P}(\mathrm{mm})$} & $2006-2015$ & 10.1 & 20.2 & 23.3 & 50.8 & 156.6 & 143.9 & 219.2 & 304.2 & 239.9 & 65.8 & 22.0 & 12.6 & 1268.6 \\
& RCP2.6 & 8.9 & 26.3 & 44.7 & 85.7 & 198.0 & 194.6 & 172.3 & 257.3 & 233.9 & 82.1 & 31.3 & 9.2 & 1344.2 \\
& RCP4.5 & 8.5 & 16.8 & 33.3 & 80.9 & 206.0 & 214.7 & 171.7 & 267.4 & 227.6 & 91.9 & 31.4 & 6.4 & 1356.6 \\
& RCP8.5 & 8.2 & 29.0 & 38.3 & 79.2 & 216.8 & 241.6 & 169.9 & 266.0 & 241.2 & 83.7 & 27.3 & 3.5 & 1404.7 \\
\hline \multicolumn{10}{c}{ Note: Temperature (T), Precipitation (P). }
\end{tabular}

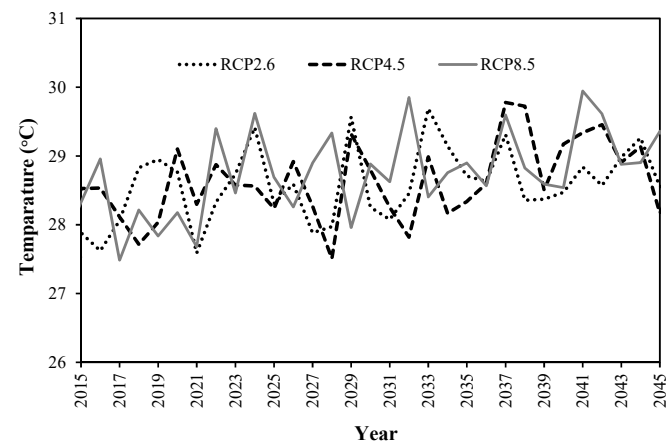

(a)

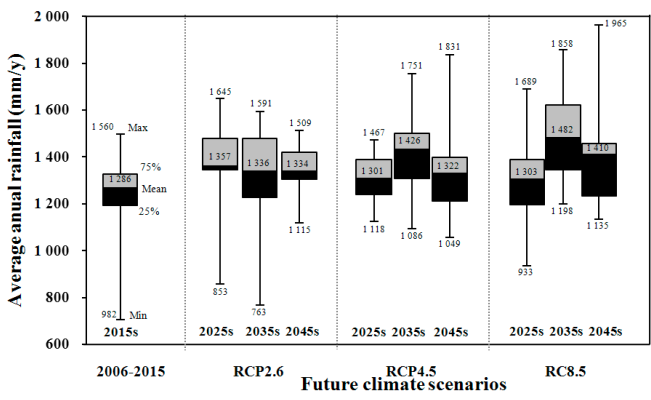

(c)

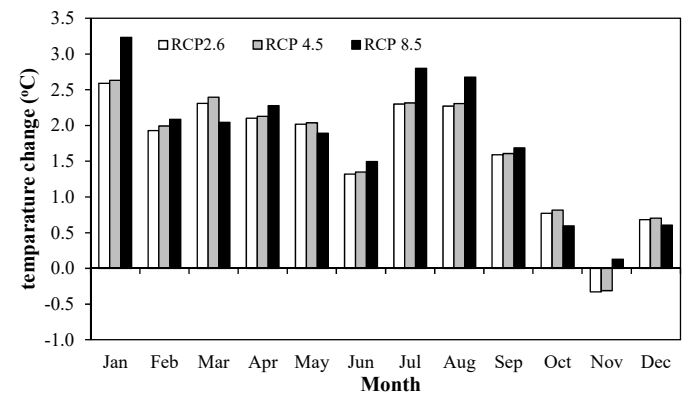

(b)

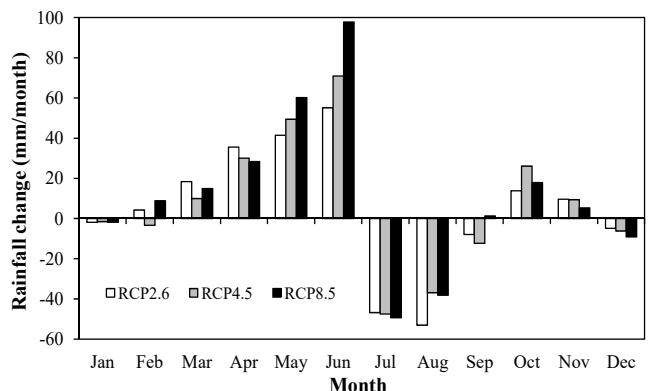

(d)

Figure 16. The projected average annual temperature (a), changes in monthly temperature from baseline (b), average annual rainfall of every 10 years (c) and changes in average monthly rainfall (d) under three climate scenarios.

Rainfall regime in the CHLB has a distinct wet season (May to October) and dry season (November to April), as shown in Table 5. Rainfall changes during the wet seasons are more distinct compared to the dry seasons. The average monthly rainfall in the climate model shows that rainfall in the wet season is expected to increase significantly in May and June, whereas, under all the scenarios, it is projected to decrease slightly during the months of July and August (Figure 16d). The distribution of rainfall that occurs in the wet season consists of about $85 \%$ of average annual rainfall, which is a decrease from the baseline of about $90 \%$.

\section{Impact of Conceptual Models and Climate Changes on Groundwater Systems}

The projected data of three climate scenarios were used to estimate future groundwater recharge using the calibrated HELP3 model. The result shows that annual groundwater recharge tends to 
increase from 2006-2015 for all scenarios of future climate (Figure 17a). Groundwater recharge in the CHLB is projected to increase by about $14.97 \%, 15.21 \%$, and $18.90 \%$, compared to the period 2006-2015, under the RCP2.6, RCP 4.5, and RCP8.5 scenarios, respectively. The proportion of recharge between wet seasons, according to the climate scenario data, is around $84.41 \%$ of annual recharge, which shows a decrease from 2006-2015 (89.29\%), due to an increase in projected rainfall during the dry seasons. Therefore, the volume and pattern of rainfall in future climates will impact the amounts of groundwater recharge.

Increasing groundwater recharge rates respond to groundwater flow, storage, and salinity, which were simulated in all scenarios by the calibrated SEAWAT model, under the four alternative conceptual models during 2016-2045. The results show that the projected water inflow to the aquifers in all scenarios of all models is more than the water outflow from the aquifers, and varies from 43.97 to 146.87.11 MCM/year; also, groundwater levels tend to increase annually for all scenarios and all models. Model A shows the highest increase in groundwater storage in the CHLB by about $28.04 \%$, $28.76 \%$, and $32.06 \%$ under the RCP2.6, RCP4.5, and RCP 8.5 scenarios, respectively, followed by models $\mathrm{B}, \mathrm{C}$ and D. The RCP8.5 climate scenario involved the greatest increase in groundwater storage for all models, followed by RCP4.5 and RCP2.6, as presented in Figure 17b. The future groundwater recharge is the most significant parameter that affects aquifer storage in the CHLB.

In addition, the change in groundwater recharge rates and aquifer storages in CHLB also altered groundwater flow and salinity distribution. The simulations of groundwater model indicate that areas of saline groundwater will increase year by year until 2045 in every scenario and every alternative conceptual model (Table 6). Groundwater salinity is extracted from four alternative conceptual models, representing similar increasing rates for all climate scenarios. The RCP8.5 scenario indicated the highest increase, followed by RCP4.5 and RCP2.6 compared to the baseline period. Groundwater salinity, extracted from model B, showed the largest increase in distribution, followed by models D, $B$, and C. This is due to model B having a shallower layer of rock salt than the initial model (model A). On the other hand, model D, like model B, has a smaller salinity area. This might be due to the conceptual model of model D adding GHBs at the boundary of the study area where Huai Luang River cuts off the basin; groundwater is allowed to flow in and flow out through the study area, so the aquifer storage volume is the lowest of all the models.

Table 6. Projected groundwater salinity and shallow water table distribution areas under future climate scenarios and different conceptual models.

\begin{tabular}{|c|c|c|c|c|c|c|c|c|c|c|c|c|}
\hline \multirow{3}{*}{ Model } & \multicolumn{6}{|c|}{ Saline Groundwater Areas } & \multicolumn{6}{|c|}{ Shallow Water Table Areas } \\
\hline & \multicolumn{2}{|c|}{ RCP2.6 } & \multicolumn{2}{|c|}{ RCP4.5 } & \multicolumn{2}{|c|}{ RCP8.5 } & \multicolumn{2}{|c|}{ RCP2.6 } & \multicolumn{2}{|c|}{ RCP4.5 } & \multicolumn{2}{|c|}{ RCP8.5 } \\
\hline & $\mathrm{km}^{2}$ & $\%$ & $\mathrm{~km}^{2}$ & $\%$ & $\mathrm{~km}^{2}$ & $\%$ & $\mathrm{~km}^{2}$ & $\%$ & $\mathrm{~km}^{2}$ & $\%$ & $\mathrm{~km}^{2}$ & $\%$ \\
\hline 2015 & 435.77 & - & 435.77 & - & 435.77 & - & 566.98 & - & 566.98 & - & 566.98 & - \\
\hline A & 482.57 & 10.74 & 487.93 & 11.97 & 493.78 & 13.31 & 865.86 & 52.71 & 938.14 & 65.46 & 985.02 & 73.73 \\
\hline B & 521.43 & 19.66 & 534.74 & 22.71 & 543.41 & 24.70 & 853.02 & 50.45 & 905.16 & 59.65 & 947.45 & 67.10 \\
\hline $\mathrm{C}$ & 457.88 & 5.07 & 465.87 & 6.91 & 476.52 & 9.35 & 762.78 & 34.53 & 839.98 & 48.15 & 883.79 & 55.88 \\
\hline $\mathbf{D}$ & 479.37 & 10.01 & 489.11 & 12.24 & 499.26 & 14.57 & 788.20 & 39.02 & 847.16 & 49.42 & 893.29 & 57.55 \\
\hline
\end{tabular}

The spatial distribution of the saline groundwater of model B of RCP8.5 shows that the area with the highest salinity (TDS $>20,000 \mathrm{mg} / \mathrm{L}$ ) will become diluted and will, thereby, become an area of moderate salinity (TDS 5000-20,000 mg/L). Moreover, the low-salinity (TDS 1000-5000 mg/L) area will expand to become a non-salinity area (Figure 18a). By 2045, the saline groundwater area (TDS $>1000 \mathrm{mg} / \mathrm{L}$ ), as projected under the RCP2.6, RCP4.5, and RCP8.5 scenarios of model B, will cover an area of $521.43 \mathrm{~km}^{2}$ (34.10\% of CHLB), $521.43 \mathrm{~km}^{2}$ (34.97\% of CHLB), and $534.74 \mathrm{~km}^{2}$ (35.54\% of CHLB), respectively. Compared to in 2015, the saline groundwater area will increase by about $19.66 \%, 22.71 \%$, and $24.70 \%$ under the RCP2.6, RCP4.5, and RCP8.5 scenarios, respectively. 
Saline groundwater areas will expand from the flood plain of the Huai Luang River to the discharge areas.

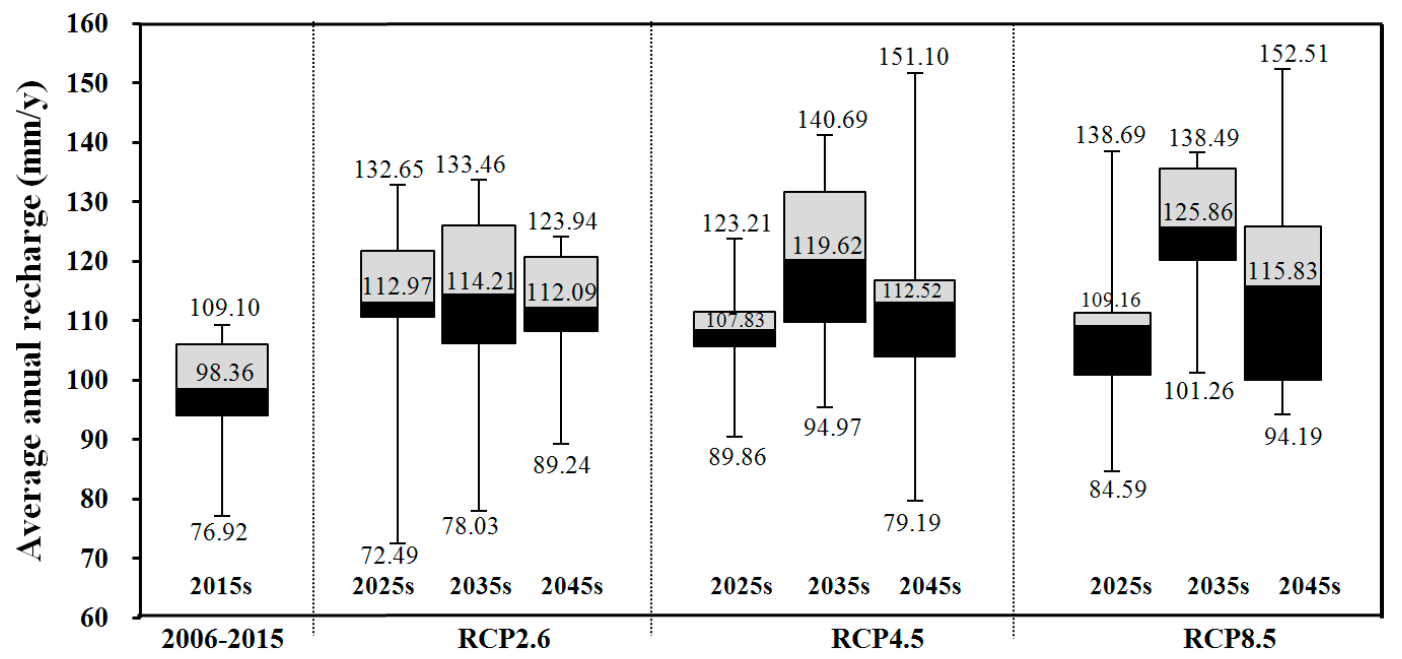

Future climate scenarios

(a)

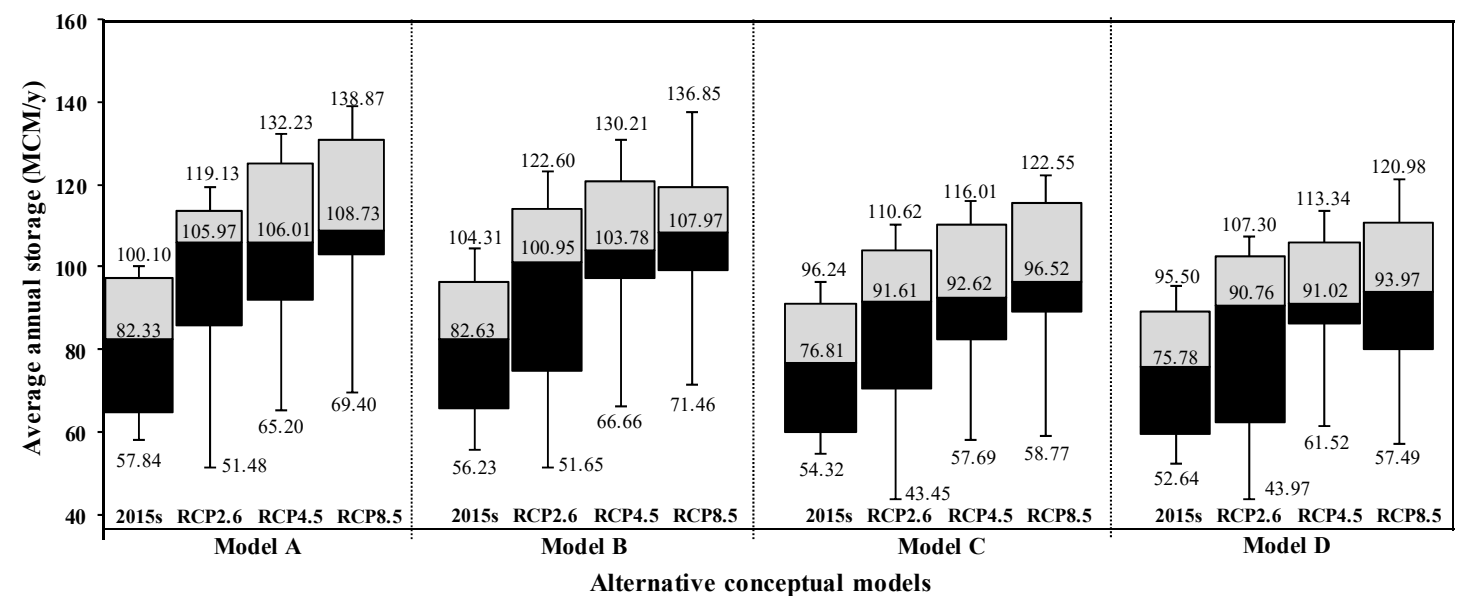

(b)

Figure 17. Simulation of future annual groundwater recharge (a) and simulations of future average annual aquifer storage of alternative conceptual models from 2016 to 2045 (b).

Furthermore, the projected groundwater system under future climate strongly indicates a significant increase in the groundwater level or water table, a result of the increase in aquifer storage. To evaluate the impact of climate change and alternative conceptual models on groundwater level, a water table shallower than $4 \mathrm{~m}$ below the ground surface (bgs) was extracted from models. Future shallow water table areas show a similar trend as saline groundwater; they gradually increase in every scenario and every model. The shallow water table area tends to extend from the discharge to the recharge areas in some areas. Model A shows the most increasing shallow water table area than other models due to its high aquifer storage, followed by models B, D, and C. Climate scenario RCP8.5 also shows the highest expansion of the shallow water table area for every model (Table 6). The spatial aspects of the shallow water table of model A under the RCP8.5 climate scenario show that areas of water table shallower than $2 \mathrm{~m}$ bgs will invade areas with water table situated about 2-4 m bgs, while the area of water table about 2-4 m bgs will expand into deeper water table areas (Figure 18b). By 2045, the shallow water table area (water table $<4 \mathrm{~m}$ ) in model B will cover an area 
of $865.86 \mathrm{~km}^{2}$ (56.63\% of CHLB), $983.14 \mathrm{~km}^{2}$ (61.36\% of CHLB), and $985.02 \mathrm{~km}^{2}(64.42 \%$ of CHLB) under the RCP2.6, RCP4.5, and RCP8.5 scenarios, respectively. The projected shallow water table area will increase from 2015 by about $52.71 \%, 65.46 \%$, and $73.73 \%$ under the RCP2.6, RCP4.5, and RCP8.5 scenarios, respectively. Increases in groundwater storage lead to rising groundwater levels, which then causes an expansion in the shallow water table area. The projected areas of shallow water table and saline groundwater, which will affect soil salinity, are thus expected to increase.

To evaluate the results of uncertainty between the different alternative conceptual models to simulate the impact on the groundwater system in the future, the results of each model were compared to the initial model (model A). Model B, which represents the difference from model A achieved by changing the depth and thickness of the rock salt of Maha Sarakham, has the higher impact on salinity distribution predictions (average total increase from model A of 9.23\%) than change in GHBs of model $\mathrm{C}$ (average total decrease from model A of $4.38 \%$ ). On the other hand, the impact on groundwater level indicates that model $\mathrm{C}$ has a higher impact on shallow water table areas' expansion (average total decrease from model A of $28.38 \%$ ) than model B (average total decrease from model A of $7.40 \%$ ).

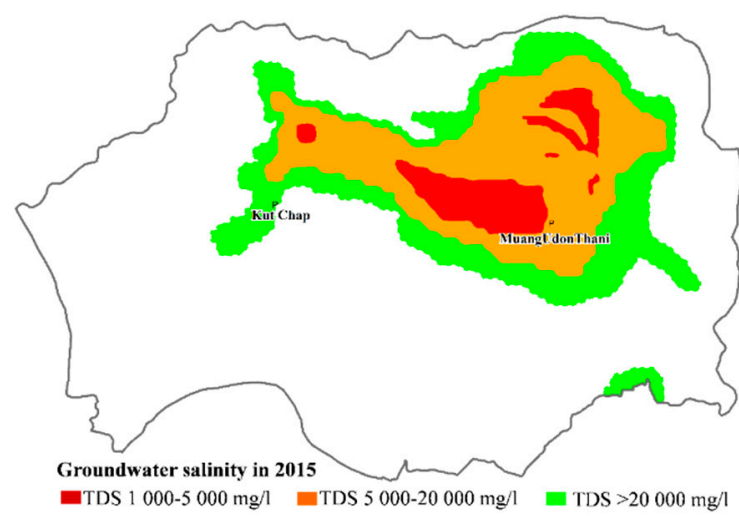

(a)

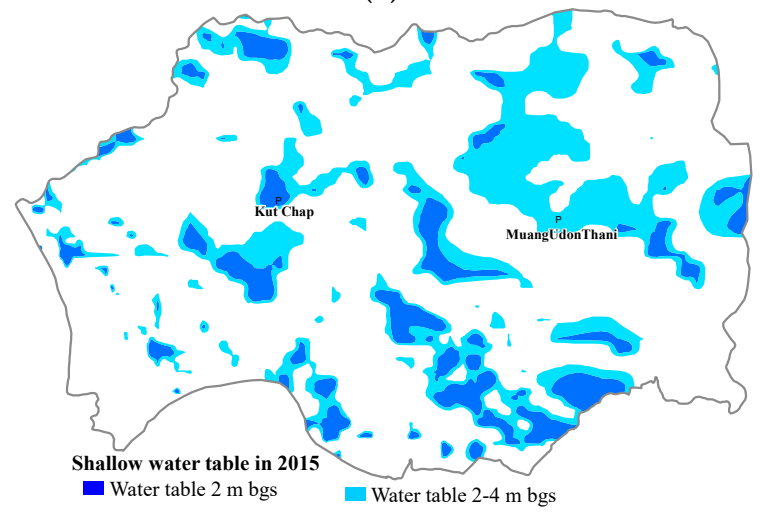

(c)

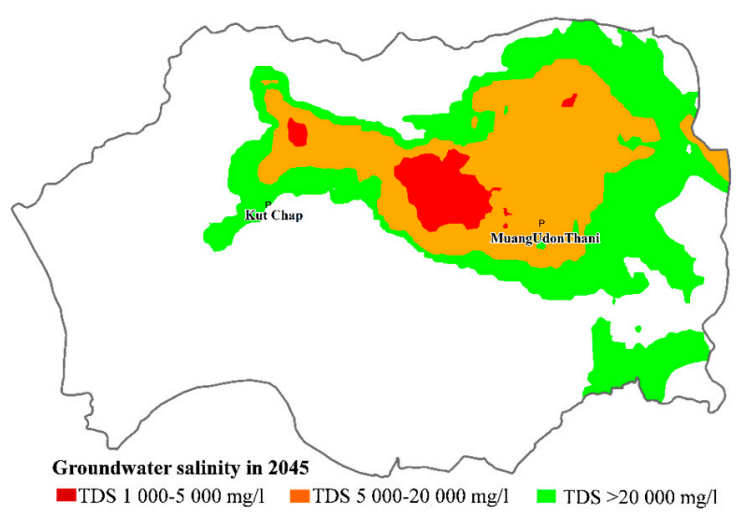

(b)

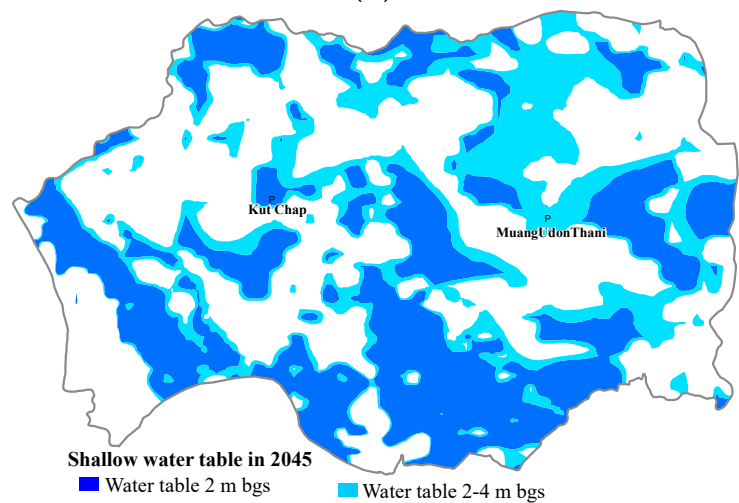

(d)

Figure 18. Groundwater salinity distribution of shallow water table. (a) Groundwater salinity distribution in 2015; (b) Groundwater salinity distribution in 2045 of model B (RCP8.6); (c) Shallow water table distribution in 2015; (d) Shallow water table distribution in 2045 of model A (RCP8.6).

\section{Sustainable Groundwater Yield}

Alley et al. [53] define sustainability as the development and use of groundwater that can be maintained indefinitely without causing unacceptable environmental, economic, or social consequences. However, each aquifer system has a unique definition of sustainable groundwater yield depending on many external environmental, ecological, and social factors. For a regular basin, the maximum sustainable yield is usually equivalent to the total inflow rate of the basin, but in salt-affected basins, groundwater quality has to be considered in the sustainability assessment. In this assessment, 
sustainable yield can be defined quantitatively through levels of groundwater decline or annual drawdown changes. When the drawdown change equals zero, or a balance between the inflow and outflow of water is achieved, the corresponding extractable rate of groundwater is the sustainable yield of groundwater development. In addition, for sustainable yield, groundwater salinity (TDS) has to be constrained to under $1000 \mathrm{mg} / \mathrm{L}$ during pumping from wells; otherwise, saline water may disperse in the vertical direction or upconing phenomena. Sustainable groundwater, by pumping across the entire of CHLB, can be simulated for 2016-2045 under the future climate scenarios. The pumping rates were divided into five zones as shown in Figure 8, according to groundwater management zones. The sustainable yield is optimized based on the assumption that the future number and distribution of wells will be the same as in 2015, and no new wells will be added to the system. Using these initial pumping rates, the groundwater simulations have been repeated many times by slowly increasing the pumping rates in each zone, until they met the sustainable yield in terms of quantitative constraint-zero drawdown, then we adjusted the pumping rate of each well until the sustainable yield achieved a TDS of less than $1000 \mathrm{mg} / \mathrm{L}$.

Table 7 summarizes the sustainable yields obtained from the four alternative models under three future climate scenarios for the groundwater management zones (Figure 7). These indicate that the new pumping wells can be placed in other locations without violating the specified constraints. For the sustainability of groundwater yields under three scenarios of future climate conditions for a total of 30 years, the results indicate that groundwater yield can exceed current pumping rates in every management zone and climate scenario. Future climate scenario RCP8.5 was proposed with the highest total groundwater yield of CHLB, followed by RCP4.5 and RCP2.6, which are more than the current groundwater abstraction by a factor of $188-403$. Considering each management zone, the sustainability groundwater yield of zones $2-5$ responded to future climate scenarios, with groundwater abstraction increasing, in order from least to most, in RCP2.5, 4.5 and 8.5. Management zone 1 does not change in future climate scenarios because it is under the salt-affected area, the pumping rates are low, and it has a limited area due to the highly saline groundwater.

Although there was a similar performance among the four alternative conceptual models of sustainable groundwater yield, total sustainable yield estimates varied substantially depending on the conceptual models applied. Model A had the highest sustainable yield, followed by models C, B, and D. The sustainable yields in each groundwater management zone in Table 7 vary more widely than the total sustainable yields among different alternative conceptual models. Model $\mathrm{C}$ had the highest sustainable yields for zones 1 and 3, which are higher than the lowest sustainable yield from model D by about $230 \%$ and $71 \%$, respectively. Model A had the largest sustainable yield in zones 2,4 , and 5 , higher than the lowest sustainable yield from model D by about $125 \%, 54 \%$, and $74 \%$, respectively. Uncertainty analysis of several possible hydrogeological models will offer more opportunities in groundwater management practice. To investigate the influence of each alternative conceptual model, the total sustainable yield of the initial model was compared to the results from other models. The change in depth and thickness of rock salt of Maha Sarakham (model B) has a higher impact on model predictions (average total sustainable yield decreases from model A by $21.83 \%$ ) than change in GHBs of model C (average total sustainable yield decreases from model A by $6.19 \%$ ). This is the same result as the impact of alternative conceptual model on sustainable groundwater yield in the Thapha area, Chi River Basin, Northeast Thailand [53] and the Hat Yai Basin, Southern Thailand [6], where it was reported that the contribution of the hydrogeologic conditions is higher than that of the boundary conditions. The depth of rock salt underlying the basin was the cause of increasing groundwater salinity distribution and the pumping rate had to meet the qualitative constraints of sustainable yield, especially in sensitive groundwater salinity areas such as zone 1 and 3 . Moreover, the configuration of the shallow rock salt layer affected the hydraulic conductivity, storage coefficient, and other relative parameters and changed the groundwater flow and storage, finally decreasing the pumping rate of sustainable yield. The total sustainable yield of model $\mathrm{C}$ decreased from the initial model due to the GHBs allowing groundwater to flow in and out of the study area. The aquifer storage 
volume also decreased from the initial model and then reduced the pumping rate of sustainable yield. Therefore, the combination of the change in depth and thickness of rock salt of Maha Sarakham and GHBs representation (model D) showed the highest impact on model predictions compared to the initial model (average total sustainable yield decreases from model A by $43.66 \%$ ).

Table 7. Sustainable groundwater yields simulated from future climate scenarios and different conceptual models according to groundwater management zones.

\begin{tabular}{|c|c|c|c|c|c|c|c|c|c|c|c|c|c|}
\hline \multirow{2}{*}{ Climate } & \multirow{2}{*}{ Model } & \multicolumn{2}{|c|}{ Zone 1} & \multicolumn{2}{|c|}{ Zone 2} & \multicolumn{2}{|c|}{ Zone 3} & \multicolumn{2}{|c|}{ Zone 4} & \multicolumn{2}{|c|}{ Zone 5} & \multicolumn{2}{|c|}{ Total } \\
\hline & & $\mathrm{m}^{3} / \mathrm{d}$ & $\%$ & $\mathrm{~m}^{3} / \mathrm{d}$ & $\%$ & $\mathrm{~m}^{3} / \mathrm{d}$ & $\%$ & $\mathrm{~m}^{3} / \mathrm{d}$ & $\%$ & $\mathrm{~m}^{3} / \mathrm{d}$ & $\%$ & $\mathrm{~m}^{3} / \mathrm{d}$ & $\%$ \\
\hline & 2015 & 2384 & - & 6309 & - & 2263 & - & 6104 & - & 1712 & - & 18,771 & - \\
\hline \multirow{4}{*}{ RCP 2.6} & A & 10,962 & 359.9 & 25,771 & 308.5 & 9923 & 338.5 & 27,425 & 349.3 & 7515 & 338.9 & 81,595 & 334.7 \\
\hline & B & 5159 & 116.4 & 22,100 & 250.3 & 7005 & 209.6 & 20,194 & 230.8 & 7472 & 336.4 & 61,929 & 229.9 \\
\hline & C & 13,760 & 477.3 & 20,854 & 230.6 & 13,113 & 479.5 & 22,799 & 273.5 & 5010 & 192.6 & 75,536 & 302.4 \\
\hline & D & 4283 & 79.7 & 11,454 & 81.6 & 7210 & 218.6 & 16,900 & 176.9 & 5266 & 207.6 & 45,113 & 140.3 \\
\hline \multirow{4}{*}{ RCP 4.5} & A & 11,089 & 365.2 & 27,782 & 340.4 & 10,921 & 382.6 & 28,453 & 366.1 & 8716 & 409.1 & 86,960 & 363.3 \\
\hline & B & 5093 & 113.7 & 23,295 & 269.2 & 8345 & 268.8 & 23,019 & 277.1 & 8047 & 370.0 & 67,799 & 261.2 \\
\hline & C & 13,784 & 478.3 & 22,779 & 261.1 & 14,041 & 520.5 & 24,411 & 299.9 & 6772 & 295.6 & 81,786 & 335.7 \\
\hline & D & 4295 & 80.2 & 12,309 & 95.1 & 7993 & 253.2 & 18,212 & 198.4 & 6197 & 262.0 & 49,007 & 161.1 \\
\hline \multirow{4}{*}{ RCP 8.5} & A & 10,289 & 331.7 & 30,817 & 388.5 & 11,151 & 392.8 & 31,660 & 418.7 & 10,528 & 514.9 & 94,444 & 403.1 \\
\hline & B & 5140 & 115.6 & 26,942 & 327.1 & 10,457 & 362.1 & 25,429 & 316.6 & 8190 & 378.4 & 76,157 & 305.7 \\
\hline & C & 13,889 & 482.7 & 24,308 & 285.3 & 15,073 & 566.1 & 28,505 & 367.0 & 7755 & 353.0 & 89,529 & 377.0 \\
\hline & D & 4202 & 76.3 & 13,678 & 116.8 & 8803 & 289.0 & 20,542 & 236.5 & 6971 & 307.2 & 54,197 & 188.7 \\
\hline
\end{tabular}

Note: \% is the increase i groundwater pumping rate in each zone compared to 2015.

\section{Conclusions and Recommendations}

A numerical model was developed as a tool for assessing the groundwater management of the salt-affected basin of CHLB aquifer system in the future. The uncertainties of the hydrogeological conceptual model and the variable of future climate were considered in future plausible scenarios of the groundwater systems and groundwater management plans in the next 30 years. The four different alternative hydrogeological conceptual model scenarios were the initial model (model A), a change in the depth and thickness of the rock salt formation from the initial model (model B), a change in boundary condition at the rim of basin from the initial model (model C), and a combination of both changes (model D). The representative variables of future climates were selected for the three climate scenarios of very severe (RCP8.5), moderate (RCP4.5), and slight (RCP2.6) changes in rainfall and temperature compared to current conditions. The impact of the alternative conceptual models on the groundwater system was evaluated in terms of the change in groundwater saline distribution and shallowness of groundwater level (water table) areas. The results indicated that the change in depth and thickness of rock salt in the Maha Sarakham conceptual model had the highest impact on groundwater saline distribution, while the change in boundary conditions at the rim of the basin had the highest impact on the expansion of shallow water table areas. In addition, the future climate in the RCP8.5 scenario had the highest impact on both groundwater salinity and shallow water table distribution. The simulated models indicate that groundwater salinity and shallow water table increase continuously in every future climate scenario and every conceptual model. The groundwater salinity and shallow water table will increase by about $50.07-24.70 \%$ and $34.53-73.73 \%$, respectively, compared to 2015 .

Groundwater management in the future of CHLB was assessed under the sustainable yield concept, the alternative conceptual models, and future climate scenarios to show that the sustainable groundwater yield estimates vary substantially. The projected pumping rates and well distributions suggest that the contribution of the rock salt depth and thickness variable is higher than that of the boundary conditions. The sustainable yield of model $\mathrm{D}$ shows a lower pumping rate than other models. The future climate of the RCP8.5 scenario also indicates the highest sustainable yield. The simulated model indicates that the current groundwater extraction rates can be exceeded by $140-400 \%$ in the next 30 years (2016-2045).

These results indicate the high impact of hydrogeological conceptual models and climate scenarios in groundwater modeling for projecting a range of future groundwater situations and sustainable 
groundwater yield. The results can be used for basin development planning and improving future groundwater development, management, and governance. In general, the uncertainty of model construction due to alternative hydrogeologic conceptual models means we must improve the predictive capability of numerical groundwater simulation in salt-affected areas by clarification of hydrogeologic characteristics, especially the variation of salt sources such as the depth and thickness of rock salt. By and large, with regard to the intensive investigation of hydrogeologic information and the monitoring of the water level and salinity fluctuations, long-term monitoring should be considered. The quantification of uncertainties of the conceptual models in the management context is required to help decision makers select and implement robust sustainable management strategies for the CHLB.

Author Contributions: K.P., P.S., and K.S. conceived and designed the methodology and experiments and supervised the modeling and findings of this work; K.P., V.C., and K.S. conducted field investigations; K.P. and P.S. performed the experiments and analyzed the data; K.S. and V.C. assisted in developing the hydrogeological framework; K.P. wrote the initial draft of the paper, and all other co-authors contributed in the revision process of the paper.

Funding: The authors gratefully acknowledge financial support from the Thailand Research Fund (TRF) under the project "Potential Impact of Climate Change on Salt-Affected Areas in Important Rice Production Areas of Udon Thani Province".

Acknowledgments: The authors would like to thank Bureau 10 of the Regional Groundwater Resources in Udon Thani Province; the Department of Groundwater Resources (DGR); the Ministry of Natural Resources and Environment and the Land Development Regional Office 5 Khon Kaen; the Land Development Department (LDD); and the Ministry of Agriculture and Cooperatives for supporting the project. We are also extremely grateful to the staff of the Royal Irrigation Department (RID) and the Thai Meteorological Department (TMD) for sharing hydrological and weather data.

Conflicts of Interest: The authors declare no conflict of interest.

\section{References}

1. National Statistical Office (NSO). Gross Provincial Product in Thailand; National Statistical Office: Bangkok, Thailand, 2017.

2. Department of Groundwater Resources (DGR). Groundwater situation of Thailand Report; Department of Groundwater Resources: Bangkok, Thailand, 2016; 253p.

3. Kresic, N.; Mikszewski, A. Hydrogeological Conceptual Site Models: Data Analysis and Visualization; Tayler \& Francis Group: Boca Raton, FL, USA, 2013; 584p.

4. Nettasana, T. Conceptual Model Uncertainty in the Management of the Chi River Basin, Thailand. Ph.D. Thesis, University of Waterloo, Waterloo, ON, Canada, 2012.

5. Wu, J.C.; Zeng, X.K. Review of the uncertainty analysis of groundwater numerical. Chin. Sci. Bull. 2013, 58, 3044-3052. [CrossRef]

6. Lukjan, A.; Swasdi, S.; Chalermyanont, T. Importance of Alternative Conceptual Model for Sustainable Groundwater Management of the Hat Yai Basin, Thailand. Procedia Eng. 2016, 154, 308-316. [CrossRef]

7. Rojas, R.; Feyen, L.; Dassargues, A. Conceptual model uncertainty in groundwater modeling: Combining generalized likelihood uncertainty estimation and Bayesian model averaging. Water Resour. Res. 2008, 44. [CrossRef]

8. Bredehoeft, J. The conceptualization model problem-Surprise. Hydrogeol. J. 2005, 13, 37-46. [CrossRef]

9. Anderson, M.P.; Woessner, W.W.; Hunt, R.J. Applied Groundwater Modeling: Simulation of Flow and Advective Transport; Elsevier Academic Press: Amsterdam, The Natherlands, 2015; 516p.

10. Troldborg, L.; Refsgaard, J.C.; Jensen, K.H. The importance of alternative conceptual models for simulation of concentrations in a multi-aquifer system. Hydrogeol. J. 2007, 15, 843-860. [CrossRef]

11. The Intergovernmental Panel on Climate Change (IPCC). Managing the Risks of Extreme Events and Disasters to Advance Climate Change Adaptation. In A Special Report of Working Groups I and II of the Intergovernmental Panel on Climate Change; Cambridge University Press: Cambridge, UK, 2012.

12. The Intergovernmental Panel on Climate Change (IPCC). Climate Change 2007: The Physical Science Basis. In Contribution of Working Group I to the Fourth Assessment Report of the Intergovernmental Panel on Climate Change; Cambridge University Press: Cambridge, UK, 2007. 
13. Kundzewicz, Z.W.; Mata, L.J.; Arnell, N.W.; Döll, P.; Kabat, P.; Jiménez, B. Freshwater Resources and Their Management; Cambridge University Press: Cambridge, UK, 2007.

14. Bates, B.C.; Kundzewicz, Z.W.; Wu, S.; Palutikof, J.P. Climate Change and Water. In Technical Paper of the Intergovernmental Panel on Climate Change; IPCC Secretariat: Geneva, Switzerland, 2008; 210p.

15. Loaiciga, H.A.; Maidment, D.R.; Valdes, J.B. Climate-change impacts in a regional karst aquifer, Texas, USA. J. Hydrol. 2000, 227, 173-194. [CrossRef]

16. Yusoff, I.; Hiscock, K.M.; Conway, D. Simulation of the impacts of climate change on groundwater resources in Eastern England. Geol. Soc. Spec. Publ. 2002, 193, 325-344. [CrossRef]

17. Jyrkama, M.I.; Sykes, J.F. The impact of climate change on spatially varying groundwater recharge in the Grand River watershed (Ontario). J. Hydrol. 2007, 338, 237-250. [CrossRef]

18. Green, T.R.; Taniguchi, M.; Kooi, H.; Gurdak, J.J.; Allen, D.M.; Hiscock, K.M. Beneath the surface of global change: Impacts of climate change on groundwater. Review papers. J. Hydrol. 2011, 405, 532-560. [CrossRef]

19. Kløve, B.; Ala-aho, P.; Okkonen, J.; Rossi, P. Possible effects of climate change on hydrological systems: Results from research on Esker aquifers in northern Finland. In Climate Change Effects on Groundwater Resources: A Global Synthesis of Findings and Recommendations; CRC Press, Tayler \& Francis Group: Boca Raton, FL, USA, 2011.

20. Saraphirom, P.; Wirojanagud, W.; Srisuk, K. Impact of climate change on waterlogging and salinity distributions in Huai Khamrian subwatershed, NE Thailand. Environ. Earth Sci. 2013, 70, 887-900. [CrossRef]

21. Pratoomchai, W.; Kazama, S.; Hanasaki, N.; Ekkawatpanit, C.; Komori, D. A projection of groundwater resources in the Upper Chao Phraya River basin in Thailand. Hydrol. Res. Lett. 2014, 8, 20-26. [CrossRef]

22. Shrestha, S.; Bach, V.T.; Pandey, P.V. Climate change impacts on groundwater resources in Mekong Delta under representative concentration pathways (RCPs) scenarios. Environ. Sci. Policy J. 2016, 61, 1-13. [CrossRef]

23. Pholkern, K.; Saraphirom, P.; Srisuk, K. Potential Impacts of Climate Change on Groundwater Resources in the Central Huai Luang Basin, Northeast Thailand. Sci. Total Environ. J. 2018, 633, 1518-1535. [CrossRef] [PubMed]

24. Zektser, I.S.; Loaiciga, H.A. Groundwater fluxes in global hydrologic cycle: Past, present, and future. J. Hydrol. 1993, 144, 405-427. [CrossRef]

25. Chinvanno, S.; Laung-Aram, V.; Sangmanee, C.; Thanakitmetavut, J. Future climate projection for Thailand and Mainland Southeast Asia using PRECIS and ECHAM4 climate models. In Technical Report 18; Southeast Asia START Regional Center: Bangkok, Thailand, 2009.

26. Manomaiphiboon, K.; Octaviani, M.; Torsri, K. Regional climate modeling using RegCM3 for Thailand: Past and ongoing activities. In Proceedings of the First China-Thailand Joint Seminar on Climate Change, Bangkok, Thailand, 23-24 March 2009.

27. Santisirisomboon, J. Statistical Downscaling of GFDL-R30 in the area of Thailand. In Proceedings of the First China-Thailand Joint Seminar on Climate Change, Bangkok, Thailand, 23-24 March 2009.

28. Thailand Research Fund (TRF). IPCC ETARC Report: State of Knowledge on the World and Thailand's Climate Change; Thailand Research Fund: Bangkok, Thailand, 2011.

29. Chinvanno, S. Adaptation to Climate Change and Strategic for Developing, Projection for Building Capacity for Adaptation to Climate Change: Case Study of in Huai Luang River Basin Thailand; Southeast Asia START Regional Center: Bangkok, Thailand, 2014.

30. Hydro and Agro Informatics Institute (HAII). The context of climate change in Thailand. In Proceedings of the ASEAN Application of Science and Technology in Disaster Risk Resilience Water Management Workshop, Bangkok, Thailand, 4 April 2016.

31. Chaowiwat, W.; Danusatianpong, P.; Sarinnapakorn, K.; Boonya, S. Extreme climate prediction for water management community network under changing climate. In Proceedings of the 22nd National Convention on Civil Engineering, Nakhon Ratchasima, Thailand, 18-20 July 2017.

32. Thai Meteorological Department (TMD). Weather Data of Udon Thani Province; Thai Meteorological Department: Bangko, Thailand, 2016.

33. Royal Irrigation Department (RID). Rainfall, Steam Flow and Irrigation Data of Udon Thani Province; Royal Irrigation Department: Udon Thani Province, Thailand, 2015.

34. Department of Mineral Resources (DMR). Geological Map of Thailand 1:250,000; Department of Mineral Resources: Bangkok, Thailand, 2009. 
35. Suwanich, P. Potash and Rock salt in Thailand. In Nonmetallic Minerals Bulletin No.2; Economic Geology Division, Department of Mineral Resources: Bangkok, Thailand, 1986.

36. Cotanont, T. The Application of Environmental Isotopes and Fractured Analysis for Sustainable Groundwater Development: A Case Study of Fractured Sandstone and Siltstone Aquifers, Udon Thani Province. Ph.D. Dissertation, Department of Geotechnology, Khon Kaen University, Khon Kaen, Thailand, 2014.

37. Thailand Research Fund (TRF). Potential Impact of Climate Change on Salt-Affected Areas in Important Rice Production Areas of Udon Thani Province; Thailand Research Fund: Bangkok, Thailand, 2017.

38. Srisuk, K. Genetic Characteristics of the Groundwater Regime in the Khon Kaen Drainage Basin, Northeast Thailand; The Department of Geology, University of Alberta: Edmonton, AB, Canada, 1994.

39. Water Quality Association. Glossary of Salt Water. Available online: http://www.wqa.org/glossary. cfmgl1874 (accessed on 25 January 2016).

40. Salinity and Contaminant Hydrology Group (SalCon). Salinity Management Handbook; Salinity and Contaminant Hydrology Group, Department of Natural Resources: Queensland, Australia, 1997.

41. The Australian and New Zealand Environment Conservation Council (ANZECC). Australian and New Zealand Guidelines for Fresh and Marine Water Quality; National Water Quality Management Strategy; Australian Water Association: New South Wales, Australia, 2000; Volume 1.

42. Deutsch, W.J. Groundwater Chemistry-Fundamentals and Applications to Contamination; Lewis Publishers: Boca Raton, FL, USA; New York, NY, USA, 1997.

43. Langevin, C.D.; Thorne, D.T., Jr.; Dausman, A.M.; Sukop, M.C.; Guo, W. SEAWAT Version 4: A computer program for simulation of multi-species solute and heat transport. In US Geological Survey Techniques and Methods Book 6, Chapter A22; U.S. Geological Survey, Florida Integrated Science Center: St. Petersburg, FL, USA, 2008; 39p.

44. Harbaugh, A.W.; Banta, E.R.; Hill, M.C.; McDonald, M.G. MODFLOW-2000, The US Geological Survey Modular Ground-Water Model-User Guide to Modularization Concepts and the Ground-Water Flow Process; U.S. Geological Survey: Reston, VA, USA, 2000; 127p.

45. Zheng, C.; Wang, P.P. MT3DMS: A Modular Three Dimensional Multispecies Transport Model for Simulation of Advection, Dispersion, and Chemical Reactions of Contaminants in Groundwater Systems; US Army Engineer Research and Development Center, University of Alabama: Washington, DC, USA, 1999; 219p.

46. Schroeder, P.R.; Dozier, T.S.; Zappi, P.A.; McEnroe, B.M.; Sjostrom, J.W.; Peyton, R.L. The Hydrologic Evaluation of Landfill Performance (HELP) Model: Engineering Documentation for Version 3; Environmental Protection Agency Office of Research and Development: Washington, DC, USA, 1994.

47. Tsai, F.; Li, X. Inverse groundwater modeling for hydraulic conductivity estimation using Bayesian model averaging and variance window. Water Resour. Res. 2010, 46, W02802. [CrossRef]

48. Jyrkama, M.I.; Sykes, J.F.; Normani, S.D. Recharge estimation for transient ground water modeling. Ground Water 2002, 40, 638-648. [CrossRef] [PubMed]

49. Scibek, J.; Allen, D.M.; Cannon, A.J.; Whitfield, P.H. Groundwater-surface water interaction under scenarios of climate change using a high-resolution transient groundwater model. J. Hydrol. 2007, 333, 165-181. [CrossRef]

50. Chylek, P.; Li, J.; Dubey, M.K.; Wang, M.; Lesins, G. Observed and model simulated 20th century Arctic temperature variability. Canadian Earth System Model CanESM2. Atmos. Chem. Phys. Discuss. 2011, 11, 22893-22907. [CrossRef]

51. Van Vuuren, D.; Edmonds, J.; Kainuma, M.; Riahi, K.; Thomson, A.; Hibbard, K. The representative concentration pathways: An overview. Clim. Chang. 2011, 109, 5-31. [CrossRef]

52. Alley, W.M.; Reilly, T.E.; Franke, O.E. Sustainability of Groundwater Resources; U.S. Geological Survey: Denver, CO, USA, 1999; 79p.

53. Nettasana, T.; Craig, J.; Tolson, B. Conceptual and numerical models for sustainable groundwater management in the Thaphra Area, Chi River Basin, Thailand. Hydrogeol. J. 2012, 20, 1355-1374. [CrossRef]

(C) 2019 by the authors. Licensee MDPI, Basel, Switzerland. This article is an open access article distributed under the terms and conditions of the Creative Commons Attribution (CC BY) license (http://creativecommons.org/licenses/by/4.0/). 